\title{
Study on Optimization of Wet Milling Process for the Development of Albendazole Containing Nanosuspension with Improved Dissolution
}

\author{
Viktor Fülöp¹, Géza Jakab¹, Bence Tóth¹, Emese Balogh¹, István Antal1* \\ ${ }^{1}$ Department of Pharmaceutics, Faculty of Pharmacy, Semmelweis University, H-1092 Budapest, Hőgyes Endre Street 7., Hungary \\ * Corresponding author, e-mail: antal.istvan@pharma.semmelweis-univ.hu
}

Received: 13 January 2020, Accepted: 08 March 2020, Published online: 24 July 2020

\begin{abstract}
The main objective of this work was to show the potential of the optimization of top-down wet planetary bead milling process parameters (milling speed, process time and size of the milling medium) by Design Of Experiments (DOE) approach for the development of albendazole (ABZ) containing nanosuspension with improved dissolution. In addition, the influence of process parameters (capacity of milling container, applied volume of milling beads, size of the milling medium, milling speed, milling time) on ABZ polymorphic transition has also been investigated. The optimized, milled formula yielded 145.39 times reduction in mean particle size (182.200 $\pm 1.3130 \mathrm{~nm})$ compared to unmilled dispersion, which demonstrated 13.50 times gain in mean dissolution rate value compared to the unmilled dispersion in medium at $\mathrm{pH}=1.2$. No lag time values were observed in the dissolution kinetics of the nanosuspension in comparison with the unmilled samples. Moreover, maximal mean solubility value was also improved by 1.45 times compared to the unmilled suspension, in medium at $\mathrm{pH}=6.8$, supporting the significance of the Ostwald-Freundlich equation. Diffraction pattern comparisons have indicated a polymorphic transition of albendazole to Form II, which was more pronounced in smaller container at high milling speed values and prolonged operations.
\end{abstract}

Keywords

albendazole nanosuspension, wet media milling, dissolution improvement, Powder X-Ray Diffractometry (PXRD), Design Of Experiments (DOE)

\begin{abstract}
1 Introduction
One of the major obstacles of the development of highly potent new drug candidates is the poor water solubility of these compounds, which hinders their therapeutic application [1]. Albendazole (ABZ) is a benzimidazoles-type, broad-spectrum anthelmintic for the treatment of intestinal helminth infections [2, 3], also showed promising results in chronic systemic therapies of cyst and echinococcus infestations [4]. This compound has a $\mathrm{pH}$ dependent, poor water solubility, a minimal of $0.016 \mathrm{mg} / \mathrm{ml}$ in $\mathrm{pH}=6.0$ buffers and a maximal of $0.376 \mathrm{mg} / \mathrm{ml}$ in medium at $\mathrm{pH}=1.2$ [5]. It has an octanol-water partition coefficient $(\log P)$ value of 3.83 [6], which is high, according to the Biopharmaceutical Classification System (BCS) drug permeability classifications [7]. As a result, ABZ is classified as a BCS Class II drug [8]. The melting point of ABZ is high, it was $197.7^{\circ} \mathrm{C}$ according to our investigations [9], in agreement with other experiment in the literature $200-230^{\circ} \mathrm{C}[10]$.
\end{abstract}

The effective dose of this compound is relatively high (200 mg human) [11] 7.5-10 mg/kg cattle and $5 \mathrm{mg} / \mathrm{kg}$ sheep in animal healthcare $[2,3]$. Pragmatic approaches for chemo-therapy of hydatid patients necessitate focusing on improved transport, targeting, modulation of the physicochemical parameters and metabolic decomposition of benzimidazoles [12]. An excellent review on recrystallizations, identification, stability and solubility evaluations of enantiotropically related albendazole polymorphs were performed by Pranzo et al. [13]. According to the authors there are two polymorphs available for ABZ, Form I (commercially available form) and Form II (recrystallized from $N, N$-dimethylformamide). Both forms proved to be physically quite stable, likely due to a high-energy barrier for the activation of the interconversion. Temperature dependent solubility studies revealed, that on $25^{\circ} \mathrm{C}$ solubility of Form I is better, than Form II. They also reported, that $80^{\circ} \mathrm{C}$ is the 
interception of the solubility vs. temperature curves, where the solid-solid transition is beginning. This observation confirms, that Form I represent the metastable polymorphs at ambient temperature. Application of a metastable Form I may be advantageous (e. g., for exploiting higher solubility in the gastrointestinal tract) only when the kinetics of conversion would be slow, namely when the energetic barrier Form I $\rightarrow$ Form II cannot be overcome during specific storage conditions. In this respect, the metastable phase should be kept cool and dry and should not be too finely subdivided [13].

Pharmaceutical nanosuspension is defined as colloidal, biphasic systems, in which solid drug particles are very finely dispersed in an aqueous vehicle, without any matrix material, stabilized by surfactants and/or polymers $[14,15]$. The particle size of the solid particles in nanosuspensions is usually less than $1 \mu \mathrm{m}$ with a mean particle size ranging between 200 and $600 \mathrm{~nm}$ [16]. The potential benefits of the nanosuspension technology for poorly soluble drug delivery are increased drug dissolution rate, increased rate and extent of absorption, hence the bioavailability of a drug (area under plasma concentration versus time curve, onset time, peak drug level), reduced variability, reduced fed/fasted effects. They have low incidence of side effects caused by the excipients, increased resistance to hydrolysis, to oxidation and physical stability to settling. Compared to microparticles nanoparticles have another outstanding feature, which is the increased adhesiveness to tissues, usually due to an increased contact area of small particles versus large particles (at identical total particle mass), which lead to improved oral absorption and penetration capability in case of topical routes of administrations [17]. Reduced administration volumes are essential for intramuscular, subcutaneous, and ophthalmic delivery. By surface modifications they can also provide the passive targeting [18-20]. The ease of scale-up and low bath-tobatch variability could be mentioned as the main advantages of the utilizations of nanosuspensions, while the most common disadvantages are high energy investment during manufacturing, immunotoxicity and non-specific uptake in reticuloendothelial system (RES) organs [18-21]. There are two converse methods available for the manufacturing of nanosuspensions. The assembling 'bottom-up' approaches, starting from molecules and building up to nano-sized particles, including microprecipitation, microemulsion and melt emulsification. The other group of techniques is referred to as 'top-down' variants, which are disintegration approaches from large particles, usually microparticles to nanoparticles, including high-pressure homogenization, media milling and there are combination methods as well, merging the advantages of both methods [22, 23].

Post processing nanosuspensions into solid dosage forms in order to improve physical stability has shown great interest e. g. spray-drying [24, 25], freeze-drying [26], fluid bed coating [27], electro-spraying [28] and hot melt extrusion [29] techniques have been successfully applied developing various formulations containing redispersable nanocrystals. An overview of albendazole containing nanosuspension formulations available in the literature have been summarized in Table 1.

Central Composite Design (CCD) is a response surface design which provides information on direct effects, pair wise interaction effects and curvilinear variable effects and is widely used for formulation and process optimization in the field of pharmaceutical product development [35]. Desirability is an objective function that ranges from zero outside of the limits to one at the goal. The optimization module searches for a combination of factor levels that simultaneously satisfy the criteria placed on each of the responses and factors. To include a response in the optimization criteria it must have a model fit through analysis or supplied via an equation only simulation. Factors are

Table 1 Albendazole nanosuspension formulation approaches available in the literature

\begin{tabular}{|c|c|c|c|}
\hline $\begin{array}{l}\text { Applied } \\
\text { method }\end{array}$ & $\begin{array}{c}\text { Utilized } \\
\text { surfactant/ } \\
\text { polymer }\end{array}$ & $\begin{array}{l}\text { Mean size or } \\
\text { size range } \\
\text { achieved }(\mathrm{nm})\end{array}$ & Reference \\
\hline $\begin{array}{l}\text { Top down } \\
\text { HPH }\end{array}$ & $\begin{array}{l}\text { Polysorbate } 80 \\
\text { Poloxamer } 188 \\
\text { HPMC }\end{array}$ & $\begin{array}{l}385.7 \pm 4.3 \mathrm{~nm} \\
420.4 \pm 6.7 \mathrm{~nm} \\
576.2 \pm 4.8 \mathrm{~nm}\end{array}$ & $\begin{array}{l}\text { Kumar et } \\
\text { al.[30] }\end{array}$ \\
\hline $\begin{array}{l}\text { Top down } \\
\text { HPH }\end{array}$ & Poloxamer 188 & $\begin{array}{l}430.2 \pm 13.2 \\
\mathrm{~nm}\end{array}$ & $\begin{array}{l}\text { Li et al. } \\
{[31]}\end{array}$ \\
\hline $\begin{array}{l}\text { Bottom up } \\
\text { Sonication } \\
\text { High speed } \\
\text { homogenization } \\
\text { Top down } \\
\text { HPH }\end{array}$ & $\begin{array}{l}\text { Polysorbate } 80 \\
\text { Poloxamer } 188 \\
\text { SLS } \\
\text { Cremophor RH } 40 \\
\text { HPMC }\end{array}$ & $\begin{array}{l}365.6 \pm 55.6 \\
\text { to } \\
753.8 \pm 74.8 \mathrm{~nm} \\
\text { dependent on } \\
\text { formulation }\end{array}$ & $\begin{array}{l}\text { Kumar et } \\
\text { al. [32] }\end{array}$ \\
\hline $\begin{array}{l}\text { Top down } \\
\text { Wet-media } \\
\text { milling }\end{array}$ & Polysorbate 80 & $\begin{array}{l}197.17 \pm 0.208 \\
\mathrm{~nm} \text { to } 200.40 \pm \\
2.318 \mathrm{~nm}\end{array}$ & $\begin{array}{l}\text { Fülöp et } \\
\text { al. [9] }\end{array}$ \\
\hline $\begin{array}{l}\text { Bottom up } \\
\text { Modified } \\
\text { emulsion } \\
\text { crosslinking } \\
\text { volatile }\end{array}$ & $\begin{array}{l}\text { Chitosan } \\
\text { Poloxamer } 188\end{array}$ & $157.8 \pm 2.82 \mathrm{~nm}$ & $\begin{array}{l}\text { Liu et al. } \\
\text { [33] }\end{array}$ \\
\hline $\begin{array}{l}\text { Bottom up } \\
\text { Modified } \\
\text { emulsion } \\
\text { crosslinking } \\
\text { volatile }\end{array}$ & $\begin{array}{l}\text { Chitosan } \\
\text { triphosphate } \\
\text { Poloxamer } 407\end{array}$ & $224.9 \pm 10.1 \mathrm{~nm}$ & $\begin{array}{l}\text { Torabi et } \\
\text { al. [34] }\end{array}$ \\
\hline
\end{tabular}


automatically included "in range". Numerical optimization uses the models to search the factor space for the best tradeoffs to achieve multiple goals. The numerical optimization finds a point, that maximizes the desirability function. The characteristics of a goal may be altered by adjusting the weight or importance. For several responses and factors, all goals get combined into one desirability function. People become distracted by trying to always get a very high desirability value. The value is completely dependent on how closely the lower and upper limits are set relative to the actual optimum. The goal of optimization is to find a good set of conditions that will meet all the goals, not to get to a desirability value of 1.0. Desirability is simply a mathematical method to find the optimum. Contour, 3D surface, and perturbation plots of the desirability function at each optimum can be used to explore the function in the factor space [36]. The desirability function can be applied for the optimization of multiple response processes finding the levels of the controllable independent factors, that provide the most desirable $Y_{i}$ response values. The $d_{i}\left(Y_{i}\right)$ uses numbers to the possible response $Y_{i}$, where $d_{i}\left(Y_{i}\right)=1$ represents a completely desirable value and $d_{i}\left(Y_{i}\right)=0$ demonstrates a completely undesirable value.

After fitting response model equations for all $Y$ variables and defining the goals, the individual desirabilities of multiple responses are combined for the overall desirability of $D$ calculating using the geometric mean function. For example, in our case for five responses (Eq. (1)) as follows:

$$
D=\left(\begin{array}{l}
\left(d_{1} \times Y_{1}\right) \times\left(d_{2} \times Y_{2}\right) \\
\times\left(d_{3} \times Y_{3}\right) \times\left(d_{4} \times Y_{4}\right) \times\left(d_{5} \times Y_{5}\right)
\end{array}\right)^{\frac{1}{5}}
$$

This article is divided into three different sections. The first section emphasizes the potential of the optimization of loading composition and formulation factors of the top down wet planetary bead milling method (Fig. 1). Our goal was to prepare ABZ nanocrystals with size distribution parameters similar to those, produced by novel modified variant of the so-called emulsion crosslinking volatile method $[33,34]$.

Process parameter optimization was performed by design of experiments (DOE) approach, which is a useful tool for the Quality by Design (QbD) concept [37]. There are numerous DOE approaches available for nanosuspension development e. g. evaluation of one variable at a time (OVAT) - type [38], $2^{2}$ - type factorial [39], $3^{2}$ - type factorial [40, 41], Box-Behnken - types [38,42].

Utilization of the microhydrodynamic models for milling parameter optimization, ideal milling beads selection and

\section{QbD (Quality by Design) \\ FORMULATION AND PROCESS PARAMETERS}

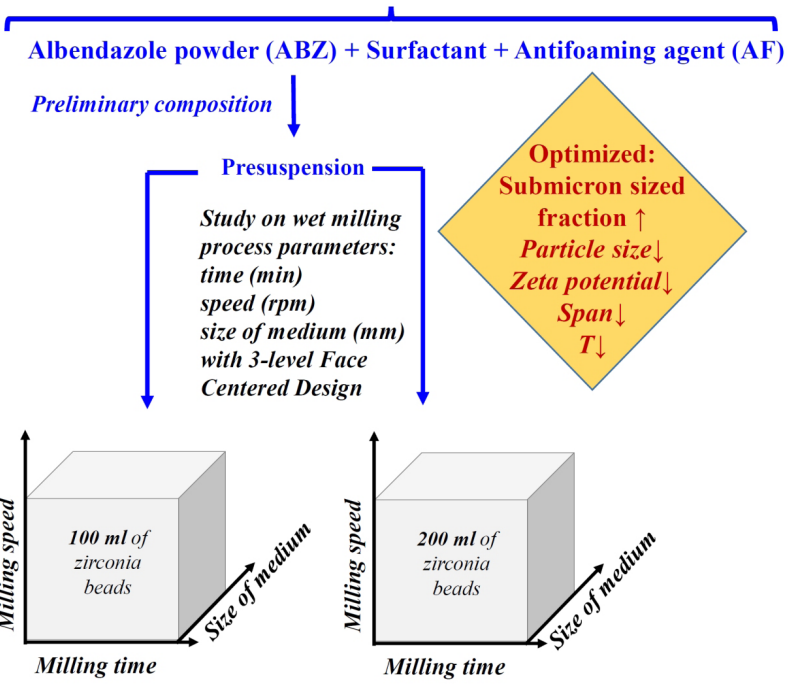

Fig. 1 Optimization of quality attributes based on design of experiments

describing their fluctuating motion during high energy Wet Stirred Media Milling (WSSM) process [43] has also gained attention in recent years [44]. Particle size distributions have been defined by dynamic light scattering and laser diffraction methods. Long term physical stability determination of the optimized nanosuspension formula as a liquid dosage form was not investigated in this study, only a short 56 days long demonstration was included. The potential stabilization principal as a reconstitutable solidified dosage form has already been reported in a previous article [9].

Section 2 focuses on in vitro solubility and dissolution studies, which describes the impact of the particle size reduction and the solubilization on the water solubility of albendazole along with the dissolution rate values in various aqueous-based $\mathrm{pH}$ buffer solutions.

Finally, Section 4 describes the influence of process parameters (capacity of the milling container, size of the milling medium, applied volume of the milling beads, milling speed, milling time) on ABZ polymorphism. It has already been reported, that mechanical stress and other sources of excess energy such as heat are inherent to milling and often lead to significant changes on the physical and chemical properties of pharmaceutical crystalline solids. Partial or complete transformation to the amorphous form, polymorphic transformations, and changes in chemical reactivity are among the frequently encountered changes produced by milling [45]. The presence of solvent can have drastic influence on the outcome of the mechanical treatment and can greatly affect the nature of the resulting material [46-50]. Crystal defects are practically unavoidable in pharmaceutical processing. Fundamental 
understanding of milling induced disorder will lead to a better process control and more consistent product performance [45]. Solid state characterization of raw material albendazole and albendazole processed in milled suspensions after drying were performed by x-ray powder diffraction analysis. The novelty of this is work is the identification of extreme milling conditions, where disadvantageous ABZ Form I $\rightarrow$ Form II conversion is realized, giving a hint to formulation scientists to avoid these conditions during ABZ nanosuspension development by wet planetary bead milling techniques.

\subsection{Theoretical}

The Ostwald-Freundlich equation (Eq. (2)) directly describes the relation between the saturation solubility of the drug and the particle size $[17,51]$ :

$\log \frac{C_{s}}{C_{\alpha}}=\frac{2 \times \sigma \times V}{2.303 \times R \times T \times \rho \times r}$,

where $C_{s}$ is the saturation solubility, $C_{\alpha}$ is the solubility of the solid consisting of large particles, $\sigma$ is the interfacial tension of substance, $V$ is the molar volume of the particle material, $R$ is the gas constant, $T$ is the absolute temperature, $\rho$ is the true density of the solid and $r$ is the radius of the particle.

It describes, that the saturation solubility $\left(C_{s}\right)$ of a drug increases with a decrease in the particle size $(r)$. However, this effect is not substantial for larger particles, but will be pronounced for materials that have a mean particle size of less than 1-2 $\mu \mathrm{m}$, especially well under $200 \mathrm{~nm}$ [17].

For volume weighted particle size distributions, such as those measured by laser diffraction, it is often convenient to report parameters based upon the maximum particle size for a given percentage volume of the sample [52]. In this article the volume weighted mean particle size $(D[4,3])$ has been chosen as one of the dependent variables in 3-factor 3-level central composite design (face centered of alpha 1) over the median particle size d50 and $90 \%$ cumulative undersize particle size $\mathrm{d} 90$. The volume weighted mean particle size or volume moment mean (De Brouckere Mean Diameter) is relevant for many samples as it reflects the size of those particles which constitute the bulk of the sample volume. It is most sensitive to the presence of large particulates in the size distribution $[52,53]$. The equation for defining the volume mean is shown below (Eq. (3)):

$$
D[4,3]=\frac{\sum_{1}^{n} D_{i}^{4} \times v_{i}}{\sum_{1}^{n} D_{i}^{3} \times v_{i}} .
$$

The $D_{i}$ value for each screened channel is the geometric mean, the square root of upper multiplied by the lower diameters. For the numerator the geometric $D_{i}$ should be taken to the fourth power and multiplied by the percentage in that channel, summed over all channels. For the denominator the geometric $D_{i}$ should be taken to the third power times the percent in that channel, summed over all channels [54, 55].

\section{Materials and methods}

\subsection{Materials}

Albendazole EP (micronized), (Sequent Scientific Ltd., India) was utilized as model drug for wet planetary bead milling operations. The influence of various surface-active agents on wet milling have been compared such as Polysorbate 80 (Tween 80) (Molar Chemicals Kft., Hungary), polysorbate 20 (Tween 20) (Molar Chemicals Kft., Hungary), sodium laurylsulphate (Molar Chemicals Kft., Hungary), hypromellose (Benecel ${ }^{\mathrm{TM}} \mathrm{E} 3$ pharm) (Ashland Inc., USA), poloxamer 407 (Lutrol $^{\circledR}$ F127), poloxamer 188 (Lutrol $^{\circledR}$ F68) (BASF, Germany), polyoxyl 35 hydrogenated castor oil (Kolliphor ${ }^{\circledR}$ EL), polyoxyl 40 hydrogenated castor oil (Kolliphor ${ }^{\circledR}$ RH40) (Sigma-Aldrich, USA). Dimethylpolysiloxane (Foamsol) (Kokoferm Kft., Hungary) was applied as antifoaming agent (AF).

\subsection{Surfactant assisted planetary bead milling process}

Determination of the preliminary composition of presuspension regarding to drug loading (albendazole concentration) and surfactants is one of the utmost importance during nanosuspension formulation development [56]. Then critical process parameter optimization of the wet planetary bead milling process was applied. All equipment and accessories (planetary ball mill, containers, beads and sieves) were provided by (Retsch Technology GmbH., Germany). PM 100 planetary ball mill, with stainless steel containers of $12 \mathrm{ml}$, $50 \mathrm{ml}$ and $500 \mathrm{ml}$ capacity and zirconium-dioxide beads with sizes of $\mathrm{d}=0.1 \mathrm{~mm}, \mathrm{~d}=0.3 \mathrm{~mm}, \mathrm{~d}=1.0 \mathrm{~mm}$ were utilized for milling. Stainless steel sieves, with mesh sizes of $\mathrm{d}=800 \mu \mathrm{m}, \mathrm{d}=180 \mu \mathrm{m}$ and $\mathrm{d}=63 \mu \mathrm{m}$, were applied to separate the beads from the milled suspensions by simply pouring the content of containers onto these sieves, avoiding aggregation by vibration. Milling temperature control was part of every milling experiment and was registered with an analog thermometer (Alla ${ }^{\circledR}$ France Sarl, France), which precision and traceability was certified. At-line control was performed immediately after milling programs have ended, top of the milling container was removed, the analog thermometer was inserted directly into the container and maximal milling temperature values were registered. 


\subsection{Ideal loading composition determination for wet media milling of albendazole}

Loading composition optimization evaluations were carried out in the smallest laboratory sized container $(12 \mathrm{ml})$, with batch sizes of $8.00 \mathrm{~g}$, at high milling speed (500 rpm), also with high volume of applied milling beads $(4.8 \mathrm{ml})$, while various milling programs, continuous operations were compared to cyclic ones, comprised of equally long milling and cooldown cycles, (5-5 minutes and 10-10 minutes, on-off) total process time was 60 minutes. For determination of albendazole loadings $1.00 \%(\mathrm{w} / \mathrm{w}), 3.00 \%(\mathrm{w} / \mathrm{w})$ and $4.00 \%(\mathrm{w} / \mathrm{w})$ were investigated. The influence of the surface-active agents and polymers on wet milling of albendazole were compared in concentrations of $0.40 \%(w / w)$. Best performed emulsifier concentration was screened between the ranges of $0.30 \%(\mathrm{w} / \mathrm{w})$ to $1.00 \%(\mathrm{w} / \mathrm{w})$, application of antifoaming agent dimethylpolysiloxane at higher concentrations $(>0.50 \%(w / w))$ was also involved. Results were evaluated by the following criteria: maximizing submicron sized fraction (\%), while minimizing volume-weighted mean particle size $D[4,3]$ ) ( $\mu \mathrm{m})$, and Span values (polydispersity or width of particle size distributions).

\subsection{Particle size distribution and zeta-potential analysis}

Particle size distributions of milled albendazole suspensions have been determined by both Laser Diffractometry (LD) and Dynamic Light Scattering (DLS). Sample preparations involved dispersing $100 \mu \mathrm{l}$ of milled suspensions dropwise in $100 \mathrm{ml}$ of demineralized water at a mixing speed of 1500 rpm poured into Mastersizer Hydro SM small volume dispersion unit, which yielded $10 \%$ laser obscurations. Sample absorbances have been measured prior to every particle sizing by an 8453-type, single beam UV-Vis spectrophotometer, (Agilent Technologies, USA) on wavelength $\lambda_{\text {max }}=633$ $\mathrm{nm}$, which is the wavelength of both red He-Ne laser beams, found in instruments Mastersizer 2000 laser diffractometer and Zetasizer nano ZSTM, (Malvern Instruments Ltd., UK) two angle particle and molecular size analyzer. Laser diffraction measurement were performed based on Mie scattering theory. Preset measurement parameters included the refractive index of albendazole 1.634, refractive index of dispersant water 1.333 and true density of albendazole $1.3 \mathrm{~g} \mathrm{ml}$. True density of materials is required for specific surface area calculations from size distribution parameters. General purpose measurement with enhanced sensitivity mode was utilized, which is suitable for sample characterizations containing irregular shaped particles. Every sample was measured five times individually and the mean \pm standard deviation values were reported in the results section. Recorded parameters were submicron sized fractions (\%), volume-weighted mean particle sizes $(D[4,3](\mu \mathrm{m}))$ and span values. Submicron sized fractions (\%) were calculated from the cumulative undersize distribution curves. Each measurement took 20 seconds to perform suggested by the Malvern diffraction application v.5.60.10.0 (Malvern Instrument Ltd., UK), to allow slow moving larger aggregates to pass through the detector array.

Final, optimized nanosuspension formula has also been characterized by DLS method as well. For that, $1 \mathrm{ml}$ of dispersed, diluted nanosuspension (described above) has been withdrawn from the small volume dispersion unit and were poured into a PCS 1115 glass sizing cuvette with square aperture (Malvern Instruments Ltd., UK). DLS measurement settings: Automatic, NIBS (Non-Invasive-Backscattering) mode with laser angle $173^{\circ}, 28-32$ sub runs/measurement, run durations: $10 \mathrm{~s}$. Sample chamber was heated to $25.0^{\circ} \mathrm{C}$, and equilibration time was 300 seconds. Automatic laser positioning and attenuation have been predescribed for DTS Application v.7.11.07073 (Malvern Instruments Ltd., UK), also five individual measurements were performed, for every sample and the mean \pm standard deviation values were reported for all the DLS parameters, including: intensity-weighted mean hydrodynamic diameter (Z AVG d) and Polydispersity Index (PDI) values in this article. In drug delivery applications a PDI value of less, than 0.3 is preferred for homogenous, narrow particle size distributions [57].

Zeta-potential gives certain information about the surface charge properties and further the long-term physical stability of the nanosuspensions. In order to obtain an electrostatically stabilized nanosuspension, a minimum zeta potential of $\pm 30 \mathrm{mV}$ is required. In case of a combination of electrostatic and steric stabilization, a minimum zeta potential of $\pm 20 \mathrm{mV}$ is desirable [58-60]. Zeta-potential values were also recorded with Zetasizer nano ZS ${ }^{\text {TM }}$ Electrostatic Light Scattering (ELS) method. Sample preparations involved carefully pouring $750 \mu \mathrm{l}$ of diluted milled samples into DTS 1070 capillary folded, disposable Zeta cells (Malvern Instruments Ltd., UK) to avoid the formation of bubbles in capillaries, which can mislead measurement results.

Zeta-potential distributions were registered in automatic mode from 5 parallels after 300 seconds equilibration time at $25{ }^{\circ} \mathrm{C}$ and the mean \pm standard deviation values were reported. Dispersant viscosity correction was not necessary, because surfactant concentration and milled 
active content of diluted samples was $0.0005 \%(\mathrm{w} / \mathrm{w})$ and $0.00365 \%(\mathrm{w} / \mathrm{w})$ respectively, which had negligible impact on dispersant viscosity.

\subsection{Process parameter optimization of wet-milling by factorial design and desirability approach}

Out of all the experimental designs, Central Composite Designs (CCD) have been extensively used to optimization of manufacturing processes.

In order to characterize the relationship between formulation factors and their impact on the output variables response surface methodology based on face centered central composite design was utilized.

The sizes of zirconia beads, the milling speed and the milling time values can significantly influence the quality performance of nanosuspensions. In this study these were the analyzed formulation variables. Milling experiments were carried out in $500 \mathrm{ml}$ containers, with two different volumes of milling beads (100 $\mathrm{ml}$ and $200 \mathrm{ml})$ as category factors, where batch sizes were $425.5649 \mathrm{~g}$ and $476.1498 \mathrm{~g}$ respectively. A three-level $(+1,0,-1)$ factorial design for the optimization of the independent variables with $32-32$ runs (5-5 center points) was applied to each category. Submicron sized fraction (\%) $\left(Y_{1}\right)$, volume-weighted mean particle size $(D[4,3])(\mu \mathrm{m})\left(Y_{2}\right)$, span of particle size distributions $\left(Y_{3}\right)$, zeta-potential $(\mathrm{mV})\left(Y_{4}\right)$ and milling temperature $\left({ }^{\circ} \mathrm{C}\right)\left(Y_{5}\right)$ values were selected as responses (dependent variables) (Table 2). Experiments were run in random order to increase the predictability of the quadratic models. The following 3-level factorial polynomial equation was fitted to the measurement data (Eq. (4)):

$$
\begin{aligned}
& Y_{n}=b_{0}+b_{1} X_{1}+b_{2} X_{2}+b_{3} X_{3}+b_{12} X_{1} X_{2} \\
& +b_{13} X_{1} X_{3}+b_{23} X_{2} X_{3}+b_{11} X_{1}^{2}+b_{22} X_{2}^{2}+b_{33} X_{3}^{2},
\end{aligned}
$$

where $Y_{n}$ were the dependent variables; $b_{0}$ was the intercept, the arithmetic mean of all quantified outcomes of 32 runs; $b_{1}, b_{2}, b_{3}$ were the individual polynomial coefficients describing the influence of each parameter on the outcome; $b_{12}, b_{13}, b_{23}$ were the coefficients of the interaction functions; $b_{11}, b_{22}, b_{33}$ were the coefficients of the quadratic functions; $X_{1}, X_{2}, X_{3}$ values were the independent variables, where $X_{1}$ represented the milling time (20, 40 and 60 minutes long programs were screened), $X_{2}$ represented the milling speed (effect of 200, 400 and $600 \mathrm{rpm}$ on wet milling were investigated) and $X_{3}$ represented the sizes of milling beads (effect of $d=0.1, d=0.3$ and $d=1.0$ $\mathrm{mm}$ sized zirconia beads on wet milling were compared).

The optimization and statistical experiments were designed and evaluated using the Design-Expert ${ }^{\mathbb{B}}$ software version 7.0.0 (Stat-Ease ${ }^{\circledR}$ Inc., USA). A quadratic polynomial 3-level factorial response surface design type has been predescribed, with no blocks.

Numerical optimization preset evaluation conditions included: maximizing submicron sized fraction, with target set to $100 \%$, with importance set to the maximal $5(+)$, minimizing volume-weighted mean particle size, where upper target was $D[4,3])(\mu \mathrm{m})<0.600 \mu \mathrm{m}$, importance $5(+)$ maximal, minimizing span (width of particle size distributions), importance $3(+)$, minimizing zeta-potential $(\mathrm{mV})$, where upper target was $<-30 \mathrm{mV}$, importance $5(+)$ maximal and also minimizing milling temperature $\left({ }^{\circ} \mathrm{C}\right)$ values, with upper target of $<40{ }^{\circ} \mathrm{C}$, importance $5(+)$ maximal. For end-product process parameter selection economical purposes were also taken into consideration, such as maximizing loading and yield, while minimizing energy consumption (milling speed and process time) with importance set to $3(+)$ (Table 3$)$.

\subsection{Thermodynamic solubility studies}

Thermodynamic solubility studies were determined using a slightly modified version of the classical saturation shakeflask method in dissolution media at $\mathrm{pH}=1.2(0.1 \mathrm{~N}$ hydrochloric acid), $\mathrm{pH}=4.5$ (phosphate-buffer) and $\mathrm{pH}=6.8$ (phosphate-buffer). Albendazole powder $(10 \mathrm{mg}$ ), milled and unmilled surfactant dispersions containing $10 \mathrm{mg}$ of albendazole were poured into $10 \mathrm{ml}$ volumetric vials, an additional $5 \mathrm{ml}$ of dissolution media were added to the samples.

Vials were sealed and the contents of the vials were mixed at speed $800 \mathrm{rpm}$ and heated to $37{ }^{\circ} \mathrm{C}$ with heatable magnetic stirrer MS-H-S10 (DLAB Instruments Ltd., China) and magnetic stirrer bars for 24 hours, then sedimentation was utilized for another 24 hours on $37{ }^{\circ} \mathrm{C}$ as well. It has already been reported by Baka et al. [61], that the safest way for phase separation is sedimentation, although diluted milled samples formed stable colloidal systems, where sedimentation was not enough for phase separation [61]. Thus, aliquots were taken and centrifuged at $14000 \mathrm{rpm}$ for $15 \mathrm{~min}$ using a MicroGen 16-type (Herolab GmbH, Germany) centrifuge. To avoid dissolved ABZ absorption of syringe mounted membrane filters and to increase precision and reproducibility, membrane filtering has been ignored, only centrifugation had been utilized for phase separation [62]. Complete phase separation has been confirmed by transmittance analysis and Dynamic Light Scattering particle sizing methods. Three clean supernatants were taken and measured. The mean thermodynamic solubility values $(\mu \mathrm{g} / \mathrm{ml}) \pm$ SDs were calculated from the linear calibrations in each dissolution medium 
Table 2 Independent variables with levels and goals for the construction of DOE

\begin{tabular}{|c|c|c|c|c|c|c|c|c|}
\hline Volume of milling beads & \multirow{3}{*}{ Code } & \multirow{2}{*}{\multicolumn{3}{|c|}{$\begin{array}{l}100 \mathrm{ml} \\
\text { Levels }\end{array}$}} & \multicolumn{3}{|c|}{$200 \mathrm{ml}$} & \multirow{3}{*}{ Goals } \\
\hline \multirow{2}{*}{ Independent variable } & & & & & & Levels & & \\
\hline & & -1 & 0 & +1 & -1 & 0 & +1 & \\
\hline Milling time (mins) & $X_{1}$ & 20 & 40 & 60 & 20 & 40 & 60 & Min. \\
\hline Milling speed (rpm) & $X_{2}$ & 200 & 400 & 600 & 200 & 400 & 600 & Min. \\
\hline Sizes of milling beads $(\mathrm{mm})$ & $X_{3}$ & 0.1 & 0.3 & 1.0 & 0.1 & 0.3 & 1.0 & None \\
\hline
\end{tabular}

Table 3 Preset nanosuspension criteria for the evaluation of dependent variables with numerical optimization of desirability function

\begin{tabular}{lcccc}
\hline Volume of milling beads & & & & \\
Dependent variable & Code & Target & Goals & Target \\
\hline Submicron sized fraction $(\%)$ & $Y_{1}$ & $Y_{1}=100$ & Max. & $Y_{1}=100$ \\
$D[4,3](\mu \mathrm{m})$ & $Y_{2}$ & $Y_{2}<0.600$ & Min. & $Y_{2}<0.600$ \\
Span & $Y_{3}$ & None & Min. & None \\
Zeta-potential $(\mathrm{mV})$ & $Y_{4}$ & $Y_{4}<-30$ & Min. & $Y_{4}<-30$ \\
Milling temperature $\left({ }^{\circ} \mathrm{C}\right)$ & $Y_{5}$ & $Y_{5}<40$ & Min. & $Y_{5}<40$ \\
\hline
\end{tabular}

and were determined by spectrophotometry on the absorption maximum of albendazole at wavelength $\lambda_{\max }=291$ nm, measured by an 8453-type UV-Vis spectrophotometer (Agilent Technologies, USA).

\subsection{Iv-vitro dissolution study of nanosuspensions and surfactant dispersions}

Dissolution tests were performed using Hanson SR - 8 Plus $^{\mathrm{TM}}$ Dissolution Test Station (Teledyne Hanson Research Inc., USA) by USP apparatus 2 (paddles) methods at $75 \mathrm{rpm}$ rotation speeds and $37 \pm 0.2{ }^{\circ} \mathrm{C}$ bath temperatures. For sampling Autoplus Maximizer and Autoplus MultiFill, (Teledyne Hanson Research Inc., USA) were utilized. Dissolution kinetics of optimized nanosuspensions, unmilled surfactant dispersions and raw albendazole powders were investigated in $900 \mathrm{ml}$ aqueous-based buffer solutions at $\mathrm{pH}=1.2$ (Ph. Eur. 9) (in doses of $200 \mathrm{mg}$ ), $\mathrm{pH}=4.5$ phosphate buffer solution (Ph. Eur. 9) (in doses of $100 \mathrm{mg}$ ) and $\mathrm{pH}=6.8$ phosphate buffer solution (Ph. Eur. 9) (in doses of $100 \mathrm{mg}$ ). At predetermined time-points $5 \mathrm{ml}$ samples were withdrawn from the vessels and filtered through P/N FIL10S-HR $10 \mu \mathrm{m}$ pore sized full flow membrane filters (Quality Lab Accessories L.L.C., USA) placed on the e-probes. Samples were collected in offline mode to $16 \mathrm{x}$ 100-type test tube holder rack. After every sampling, media replacement was accomplished by $5 \mathrm{ml}$ of fresh buffer solutions. Collected samples were filtered through $0.1 \mu \mathrm{m}$ pore sized polyether sulfonate (PES) syringe membrane filters (Nantong FilterBio Membrane Co. Ltd., China) prior to measurements, in order to remove undissolved particles.

Dissolution studies were performed in triplicates and the cumulative drug release (\%) mean values \pm SDs were calculated from the linear calibrations in the defined dissolution media, determined by UV-Vis spectrophotometry on the absorption maximum of albendazole at wavelength $\lambda \max =291 \mathrm{~nm}$, measured by an 8453-type UV-Vis spectrophotometer (Agilent Technologies, USA). Kinetic evaluations were performed by smoothening fitting with Excel 2016, (Microsoft Corp., USA) solver plug-in (minimizing differences between measured and calculated values), followed by Weibull-model fitting.

\subsection{Maximizing albendazole yield after optimized milling process}

Economic considerations necessitate the maximization of yield for cost effective manufacturing. In order to do so, several washing experiments have been performed and compared by an additional $16.66 \%$ (w/w) of suspension loading of surfactant solution added to separated beads in milling container with $500 \mathrm{ml}$ capacity, surfactant solution consisted of $0.5 \%(\mathrm{w} / \mathrm{w})$ Tween 80 and $0.01 \%(\mathrm{v} / \mathrm{v})$ of antifoaming agent dimethylpolysiloxane. The operation was repeated by the addition of twice $16.66 \%(\mathrm{w} / \mathrm{w})$ container mass loading, followed by $33.33 \%(w / w)$, then twice of $33.33 \%(w / w)$. An additional milling cycle was applied after every surfactant solution addition to separated beads on $300 \mathrm{rpm}$ milling speed for 5 minutes followed by another separation on stainless steel sieve with mesh size of $d=63$ $\mu \mathrm{m}$. Collected and diluted nanosuspensions were mixed with milled ones on heatable magnetic stirrer MS-H-S10 (DLAB Instruments Ltd., China) at a stirring speed of 600 rpm, with a homogenization time of 5 minutes. Drug loading, particle sizing and zeta-potential determinations were performed after each washing experiment in order to study 
the effect of dilution on dosage, particle size distribution parameters and physical stability.

\subsection{Drug content determination of milled $A B Z$ suspensions}

Albendazole has $\mathrm{pH}$ dependent poor water solubility, with a maximum at $\mathrm{pH}=1.2$ (see Subsection 3.4) as a weak alkaline compound, it was evident to determine the amount of active content in highly diluted stock solutions at $\mathrm{pH}=1.2$ ( $\mathrm{Ph}$. Eur. 9). Three stock solutions have been prepared by adding $0.25 \mathrm{ml}$ of milled ABZ suspensions to $0.1 \mathrm{~N}$ hydrochloric acid in $250 \mathrm{ml}$ volumetric flasks. Final volumes were completed to $250 \mathrm{ml}$ (1000 times dilution) mixed on heatable magnetic stirrer MS - H-S10 (DLAB Instruments Ltd., China) at stirring speed $1000 \mathrm{rpm}$, with a homogenization time of 60 minutes. Stock solutions were transparent, and no floating, undissolved particles were registered. Mean administration volume values $(\mathrm{ml}) \pm \mathrm{SDs}$ of nanosuspensions containing $200.0 \mathrm{mg}$ were calculated from the linear calibration of ABZ by UV-Vis spectrophotometry on the absorption maximum of albendazole at wavelength $\lambda_{\text {max }}=291 \mathrm{~nm}$, measured by an 8453-type UV-Vis spectrophotometer (Agilent Technologies, USA).

\subsection{Short-term physical stability evaluations of optimized, milled ABZ nanosuspension}

Short-term physical stability evaluation of the optimized formula was tracked by registering particle size distribution parameters and zeta-potential values at predetermined storage intervals: 1, 2, 3, 24, 48, 72, 168, 336, 672, 1344 hours at $25{ }^{\circ} \mathrm{C} 60 \%(\mathrm{RH})$ and at $4{ }^{\circ} \mathrm{C} 60 \%(\mathrm{RH})$ storage conditions. Samples were stored in $25 \mathrm{ml}$ volumetric brown vials, protected from direct sunlight. Each sample was shaken manually for ten seconds prior to investigations. For particle size distribution and zeta-potential measurement settings, see Subsection 2.4.

\subsection{Powder X-ray Diffractometry (PXRD), diffraction pattern comparison of solids}

Diffraction patterns were measured on PANalytical X'Pert3 Powder diffractometer (Malvern Panalytical B.V., The Netherlands) using $\mathrm{Cu} \mathrm{K \alpha}$ radiation with $45 \mathrm{kV}$ accelerating voltage and $40 \mathrm{~mA}$ anode current over the range of 5-40 $(2 \theta)$ with 0.0084 step size and $99.695 \mathrm{~s}$ times per step in reflection mode, spinning the sample holder by $1 \mathrm{~s}^{-1}$ rotation speed. Incident beam optics consisted of a programmable divergence slit with $15 \mathrm{~mm}$ constant irradiated length and an anti - scatter slit at fixed 2. Diffracted beam optics consisted of $\mathrm{X}^{\prime}$ Celerator Scientific ultra-fast line detector with 0.02 soller slit and programmable anti-scatter slit with $15 \mathrm{~mm}$ constant observed length. Single crystalline silicon zero-background diffraction plates were utilized in case of diffraction pattern comparisons of raw material ABZ powder, albendazole processed in milled and in unmilled suspension forms after drying. Sample preparations involved pouring the milled and unmilled ABZ suspensions into Petri dishes and dried slowly in AccuDry ${ }^{\circledR}$ drying chamber (Dynatech Scientific Labs, USA) on $40.0{ }^{\circ} \mathrm{C}$, for 2 days under air atmosphere and pressure. Dried powders were gently removed from dishes and sieved through a $30 \mu \mathrm{m}$ mesh size stainless steel sieve (Retsch Technology GmbH., Germany) before analysis. Data were collected by PANalytical Data Collector Application, version 5.5.0.505 (Malvern Panalytical B.V., The Netherlands).

\section{Results and discussion}

\subsection{Ideal loading composition determination for wet planetary bead milling of albendazole}

Milling trial comparisons with $\mathrm{d}=1.0 \mathrm{~mm}$ sized beads, surfactant concentrations of $0.40 \%(\mathrm{w} / \mathrm{w})$ Tween 80 and drug loadings of $3.00 \%(\mathrm{w} / \mathrm{w})$ albendazole revealed, that zirconium-dioxide beads seemed to be the ideal choice, according to predetermined criteria (see end of Subsection 2.3). There was no difference in milling temperature values; it was $29^{\circ} \mathrm{C}$ after each milling experiment.

To increase performance by increasing total contact points between surfaces, we switched to $d=0.3 \mathrm{~mm}$ sized zirconia beads for further investigations. As expected, milling temperature values have massively increased on $500 \mathrm{rpm}$ milling speed, with continuous operations. To offset this phenomenon, various cyclic operations have been introduced and compared, in order to keep the milling temperature as low as possible. We have registered the heating and cooldown rates of loadings and found out, that based on the utilized milling speed, milling time and container size, it took 30-80 minutes to cooldown to room temperature at $200 \mathrm{ml}$ of applied beads. The slow cooldown rates were compensated by limited milling time, rotation speed to obtain ABZ nanosuspensions. We have compared shorter and longer programs, with equally long cooldown cycles (5:5 (mins), 10:10 (mins) on: off) and continuous operations. After 60 minutes of milling sessions, the milling temperature values were $31.0^{\circ} \mathrm{C}, 38.0^{\circ} \mathrm{C}$ and $60.0^{\circ} \mathrm{C}$ respectively. Both milling temperature values and particle size distribution evaluation results favored the selection of 5:5 (mins) (on: off) milling program. Fig. 2 shows the 
results of loading composition optimization for wet planetary bead milling of ABZ.

During a milling process, selection of stabilizer(s) is the crucial step for successful accelerated breakdown of raw materials (Rehbinder effect) [63, 64] and stabilization of newly formed nanocrystals, reported as the first step in the Quality by Design concept of nanosuspension development [56]. In order to compare surface-active agents, that were the most ideal for wet planetary bead milling of ABZ, two non-ionic (Tween 20 and 80), one anionic (SLS) emulsifiers, four triblock copolymers (poloxamer 407 and 188, macrogolglicerol-hidroxystearate, macrogolglicerol-ricinoleate) and two water soluble polymers (PVP K30, HPMC) with low molecular weight values in concentrations of $0.40 \%(\mathrm{w} / \mathrm{w})$ have been tested. All types of surfactants, along with water soluble polymers poloxamer 407, PVP K30 and HPMC showed promising results. Best performed emulsifier however was Tween 80 considering all registered parameters. It seemed emulsifier/ polymer type had no impact on milling temperature values, $31.0^{\circ} \mathrm{C}$ was measured in all cases. Ideal surface-active agent (Tween 80 ) concentration was also screened between the concentration rage of $0.30 \%(\mathrm{w} / \mathrm{w})$ to $1.00 \%(\mathrm{w} / \mathrm{w})$ with and without antifoaming agent dimethylpolysiloxane in $0.01 \%(\mathrm{v} / \mathrm{v})$ at above $0.50 \%(\mathrm{w} / \mathrm{w})$ emulsifier, suggested by the user's manual of Foamsol.

Above $0.40 \%(\mathrm{w} / \mathrm{w})$ Tween 80 submicron sized fractions were about $90 \%$, highest value $(92.89 \%)$ registered at $0.50 \%(\mathrm{w} / \mathrm{w})$ Tween $80+0.01 \%(\mathrm{v} / \mathrm{v})$ dimethylpolysiloxane solutions, increasing amount of Tween 80 had a positive impact on polydispersity (span) values. Application of antifoaming agent in this concentration slightly increased submicron sized fraction from $86.84 \%$ to $92.89 \%$ and had no impact on polydispersity, although significantly improved milled suspension average yield from $50.12 \%(\mathrm{w} / \mathrm{w})$ to $60.53 \%(\mathrm{w} / \mathrm{w})$ after the separation from beads. Ideal drug loading investigations involved the screening of $1.00 \%, 3.00 \%$ and $4.00 \%$ (w/w) ABZ at predetermined best performed conditions. Best-case scenario was the application of $3.00 \%(\mathrm{w} / \mathrm{w})$, which yielded maximal submicron sized fraction, with minimal polydispersity values. Milling temperature values were slightly different this time, $28.0^{\circ} \mathrm{C}, 31.0^{\circ} \mathrm{C}$ and $40^{\circ} \mathrm{C}$ respectively.

\subsection{Effects of milling process parameters}

There are numerous interfering critical process parameters responsible for optimal end- product quality e.g. the type of the milling instrument, composition of the milling
A

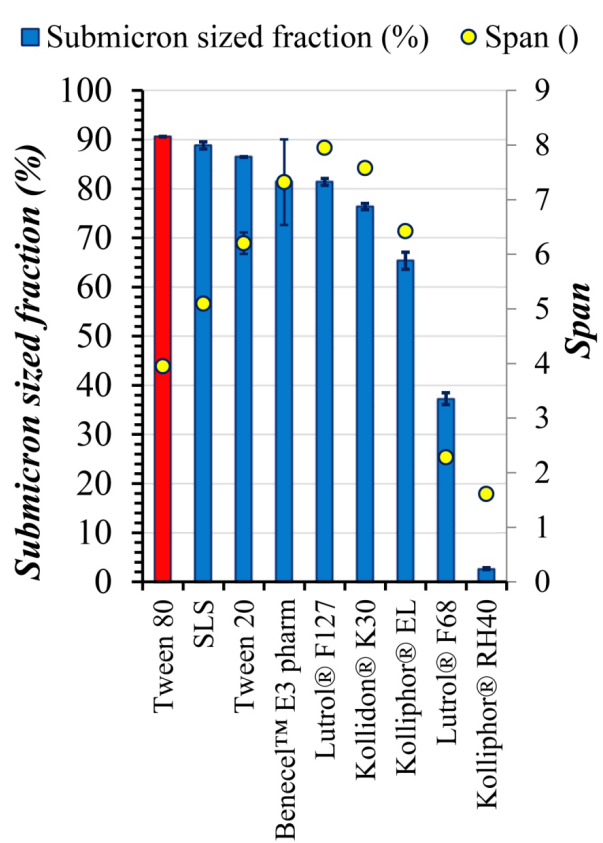

Type of emulsifier/polymer
B

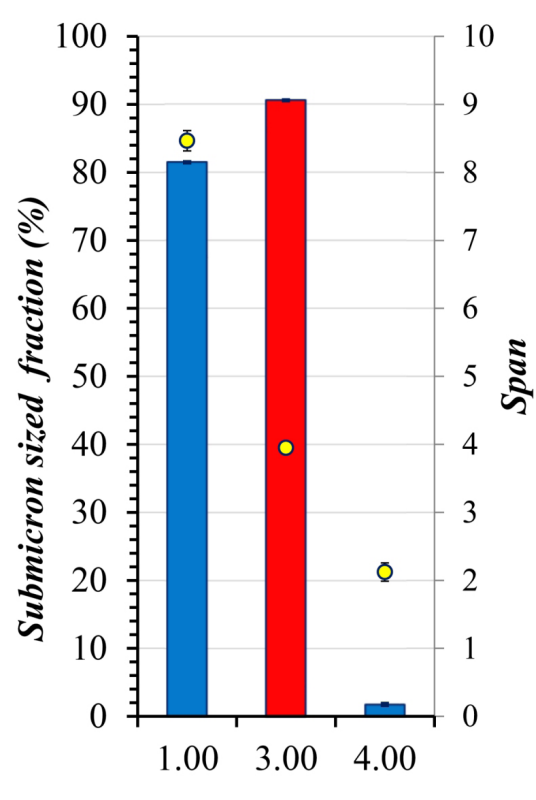

Albendazole concentration $(\% w / w)$
C

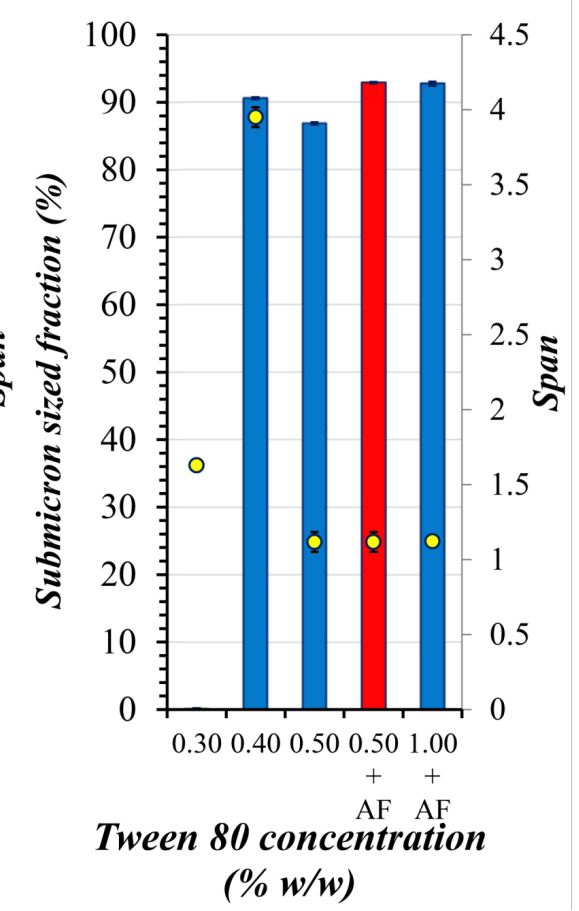

Fig. 2 Loading composition optimization for wet planetary bead milling of ABZ, A: Influence of the quality of surface-active agents and polymers, B: Influence of ABZ loading C: Influence of the quantity of Tween 80 on particle size distribution parameters measured by laser diffraction $\mathrm{n}=5$, mean values \pm SDs, where columns represent submicron sized fractions, o symbols: Span values; red color the selected composition and AF means 
medium and the inner wall of the milling container, milling speed, milling time, balls/beads to powder mass ratio, volume of the loading, milling atmosphere, milling temperature etc. [65]. The process parameters during laboratory scale planetary bead milling process were optimized for the development of albendazole containing nanosuspension using 3-factor 3-level central composite design (face centered of alpha 1) as the response surface methodology. A stepwise regression was used to build quadratic equations for each response variables. For a design space containing 3 factors with 3 levels $\left(3^{3}=27\right.$ trials), this software suggested alpha to be set to 1 and the utilization of 5 center points in the face centered design. For dependent data analysis transformations were not utilized, the software suggested the highest ordered polynomial fitting selections, where additional terms were significant and the models were not aliased, results of lack-of-fit tests were insignificant, as well as adjusted $R$-squared and predicted $R$-squared values were maximized [66].

The response (dependent) variables listed in Table 4 are fitted to a third-order polynomial model and, the regression coefficients for each term in the regression model are summarized also in Table 4 along with $R$-squared and precision values of regressions.

Every design point was well fitted to the polynoms, demonstrated by the significance of fitted models ( $p$-value $<0.05$ ), high $(>0.85)$ coefficient of determination values and high $(>10)$ signal to noise ratios indicated that, the milling experiment have been performed precisely and results were reproducible. Statistical significance ( $p$-value $<0.05$ ) of the observed parameter was indicated by * symbol.

Subsections 3.2.1-3.2.5 summarize the results of the in depth analysis of process parameters on dependent variables.

\subsubsection{Submicron sized fraction $\left(Y_{1}\right)$}

Maximizing this parameter is desirable for formulation development of nanosuspensions, therefore any factor increasing its value considered as positive impact. At 100 $\mathrm{ml}$ applied beads, the main positive effect was the quadratic function of the increasing sizes of milling beads $\left(b_{33}\right)$, which was offset by the negative effect of the increasing sizes of beads $\left(b_{3}\right)$. At $200 \mathrm{ml}$ applied beads, this phenomenon was more dominant.

\subsubsection{Volume-weighted mean particle size $\left(Y_{2}\right)$}

Minimizing this parameter is desirable for formulation development of nanosuspensions, therefore any factor decreasing its value considered as positive impact. At $100 \mathrm{ml}$ applied beads, the main driving effects of particle diminution were the interaction functions of the milling time and sizes of milling beads $\left(b_{13}\right)$ and also the milling speed and sizes of beads $\left(b_{23}\right)$, along with the increasing milling time $\left(b_{1}\right)$, which was offset by the most dominant negative effect of the increasing sizes of milling beads and the minor negative effect of the quadratic function of milling speed $\left(b_{22}\right)$.

At $200 \mathrm{ml}$ applied beads, the positive effects were the

Table 4 Polynomial model coefficients and statistical results of analysis based on the 3-factor 3-level face centered composite design (alpha 1) (statistical significance of the observed parameter indicated by * symbol, where p-value $<0.05)$ )

\begin{tabular}{|c|c|c|c|c|c|c|c|c|c|c|}
\hline \multirow[t]{2}{*}{$\begin{array}{l}\text { Polynomial coefficients/ } \\
\text { volume of applied beads }\end{array}$} & \multicolumn{2}{|c|}{$\begin{array}{c}Y_{1} \\
\text { Submicron sized } \\
\text { fraction }(\%)\end{array}$} & \multicolumn{2}{|c|}{$\begin{array}{c}Y_{2} \\
D[4,3](\mu \mathrm{m})\end{array}$} & \multicolumn{2}{|c|}{$\begin{array}{c}Y_{3} \\
\text { Span }\end{array}$} & \multicolumn{2}{|c|}{$\frac{Y_{4}}{\text { Zeta-potential (mV) }}$} & \multicolumn{2}{|c|}{$\begin{array}{c}Y_{5} \\
\text { Milling temperature } \\
\left({ }^{\circ} \mathrm{C}\right)\end{array}$} \\
\hline & $100 \mathrm{ml}$ & $200 \mathrm{ml}$ & $100 \mathrm{ml}$ & $200 \mathrm{ml}$ & $100 \mathrm{ml}$ & $200 \mathrm{ml}$ & $100 \mathrm{ml}$ & $200 \mathrm{ml}$ & $100 \mathrm{ml}$ & $200 \mathrm{ml}$ \\
\hline$b_{0}$ & +39.90 & +51.13 & +1.59 & +1.29 & +2.28 & +2.05 & -33.38 & -34.47 & +34.92 & +32.15 \\
\hline$b_{1}$ & $+4.13^{*}$ & $+3.81^{*}$ & $-0.31 *$ & $-0.26^{*}$ & $-0.22 *$ & $+0.51^{*}$ & $-0.83^{*}$ & -0.08 & +0.69 & $+1.19^{*}$ \\
\hline$b_{2}$ & +0.07 & -0.93 & $-0.18 *$ & +0.23 & -0.01 & $+0.60 *$ & $+0.66^{*}$ & $+1.26^{*}$ & $+12.44 *$ & $+7.97 *$ \\
\hline$b_{3}$ & $-34.78^{*}$ & $-34.28^{*}$ & $+1.25^{*}$ & $+1.05^{*}$ & $+0.24^{*}$ & -0.28 & $-1.88^{*}$ & $-3.33^{*}$ & $-1.56^{*}$ & $+0.97 *$ \\
\hline$b_{12}$ & +0.04 & -1.69 & $+0.14 *$ & +0.06 & +0.06 & +0.60 & $-0.48 *$ & $+1.28 *$ & +0.58 & +0.62 \\
\hline$b_{13}$ & +0.15 & $+5.22^{*}$ & $-0.35^{*}$ & $-0.62 *$ & $-0.14^{*}$ & $-1.07 *$ & -0.25 & $+0.17 *$ & +1.04 & $+1.54^{*}$ \\
\hline$b_{23}$ & $+2.01^{*}$ & +1.16 & $-0.27^{*}$ & -0.03 & $-0.21^{*}$ & -1.21 & $+1.43^{*}$ & $-1.50^{*}$ & $-2.25^{*}$ & $+1.92 *$ \\
\hline$b_{11}$ & -0.16 & -1.32 & +0.14 & +0.19 & +0.001 & -0.28 & $-1.68^{*}$ & +3.78 & -1.74 & -0.50 \\
\hline$b_{22}$ & $-4.12 *$ & -2.16 & $+0.22 *$ & -0.16 & +0.04 & -0.60 & $-1.65^{*}$ & $+2.64^{*}$ & +1.34 & +1.00 \\
\hline$b_{33}$ & $+19.81^{*}$ & $+13.27^{*}$ & +0.02 & $+0.32 *$ & $+0.21^{*}$ & $+1.30 *$ & $+1.18^{*}$ & $+6.53 *$ & $+2.68 *$ & +0.83 \\
\hline$P$-value & $<0.0001$ & $<0.0001$ & $<0.0001$ & $<0.0001$ & $<0.0001$ & $<0.0001$ & $<0.0001$ & $<0.0001$ & $<0.0001$ & $<0.0001$ \\
\hline$R$-squared & 0.9941 & 0.9819 & 0.9739 & 0.9259 & 0.9673 & 0.8547 & 0.9652 & 0.9454 & 0.9347 & 0.9584 \\
\hline Adj. $R$-squared & 0.9917 & 0.9744 & 0.9632 & 0.8956 & 0.9539 & 0.7953 & 0.9510 & 0.9230 & 0.9080 & 0.9414 \\
\hline Pred. $R$-squared & 0.9861 & 0.9570 & 0.9272 & 0.7774 & 0.9222 & 0.5982 & 0.9113 & 0.8524 & 0.8370 & 0.8944 \\
\hline Adeq. Precision & 57.686 & 33.752 & 36.226 & 20.840 & 37.552 & 17.615 & 35.516 & 22.450 & 19.258 & 28.451 \\
\hline
\end{tabular}


increasing milling time $\left(b_{1}\right)$ and the interaction function of milling time and sizes of milling beads $\left(b_{13}\right)$, which was offset by the negative effects of increasing sizes of milling beads $\left(b_{3}\right)$ and the quadratic function of the size of milling beads $\left(b_{33}\right)$.

\subsubsection{Span (polydispersity) values of particle size distributions (PSDs) $\left(Y_{3}\right)$}

Minimizing this parameter is desirable for formulation development of nanosuspensions, therefore any factor decreasing its value considered as positive impact. At $100 \mathrm{ml}$ applied beads, the main driving effects of reaching homogeneous PSDs were the increasing milling time $\left(b_{1}\right)$ and the interaction functions of milling time and sizes of beads $\left(b_{13}\right)$ along with the milling speed and sizes of beads $\left(b_{23}\right)$, which was nearly compensated by the total negative effect of the increasing sizes of milling beads $\left(b_{3}\right)$ and the quadratic function of the increasing sizes of milling beads $\left(b_{33}\right)$. At $200 \mathrm{ml}$ applied beads, the positive effect was the interaction function of the milling time and sizes of milling beads $\left(b_{13}\right)$, which was outweighed by the total negative effects of milling time $\left(b_{1}\right)$ milling speed $\left(b_{2}\right)$ and the quadratic function of the sizes of milling beads $\left(b_{33}\right)$.

\subsubsection{Zeta-potential values $\left(Y_{4}\right)$ of milled ABZ suspensions}

Minimizing this parameter is desirable for formulation development of nanosuspensions, therefore any factor decreasing its value considered as positive impact. At $100 \mathrm{ml}$ applied beads, the main positive effects were the increasing milling time $\left(b_{1}\right)$, increasing size of milling beads $\left(b_{3}\right)$, the interaction function of milling time and milling speed $\left(b_{12}\right)$ and the quadratic functions of the milling time $\left(b_{11}\right)$ along with the milling speed $\left(b_{22}\right)$. These effects were not compensated by the negative effects of the increasing milling time $\left(b_{2}\right)$, the interaction function of the milling speed and sizes of milling beads $\left(b_{23}\right)$ and the quadratic effect of the sizes of milling beads $\left(b_{33}\right)$. At $200 \mathrm{ml}$ applied beads, positive effects of the increasing sizes of milling beads $\left(b_{3}\right)$ and the interaction function of the milling speed and sizes of milling beads $\left(b_{23}\right)$, were offset by the total negative effects of the increasing milling speed $\left(b_{2}\right)$, the interaction functions of the milling time and milling speed $\left(b_{12}\right)$ along with the milling time and sizes of milling beads $\left(b_{13}\right)$ and also the quadratic functions of the milling speed $\left(b_{22}\right)$ and sizes of milling beads $\left(b_{33}\right)$.

\subsubsection{Milling temperature values $\left(Y_{5}\right)$}

Minimizing this parameter is desirable for formulation development of nanosuspensions, therefore any factor decreasing its value considered as positive impact. At $100 \mathrm{ml}$ applied beads, the main positive effects were the increasing sizes of milling beads $\left(b_{3}\right)$ and the interaction function of the milling speed and size of milling beads $\left(b_{23}\right)$, which was overcompensated by the total negative effects of the increasing milling speed $\left(b_{2}\right)$ and the quadratic function of the sizes of milling beads $\left(b_{33}\right)$. At $200 \mathrm{ml}$ applied beads, only negative effects were observed, the major one was the increasing milling speed $\left(b_{2}\right)$.

When influence of zirconia beads with different sizes were compared on milled ABZ particle size distribution parameters and suspension zeta-potential values at $100 \mathrm{ml}$ of applied zirconia beads, result showed improving performance on size reduction with the utilization of smaller beads, consequently showed inverse proportionality with the size of milling medium. Nanosuspension criteria (see end of Subsection 2.5) were easily fulfilled with the application of $d=0.1 \mathrm{~mm}$ sized beads at low to mediocre milling speed intervals (200-434 rpm), with a wide range in process time (20-59.4 mins), however coarse programs at higher rotation speeds (500 - $600 \mathrm{rpm})$ seemed to deteriorate results (Fig. 3). For explanation we should look at the 3-Dimensional response surface plots (Fig. 4). Low energy bead milling with $100 \mathrm{ml}$ of applied amount of $\mathrm{d}=0.1 \mathrm{~mm}$ sized zirconia beads was effective below

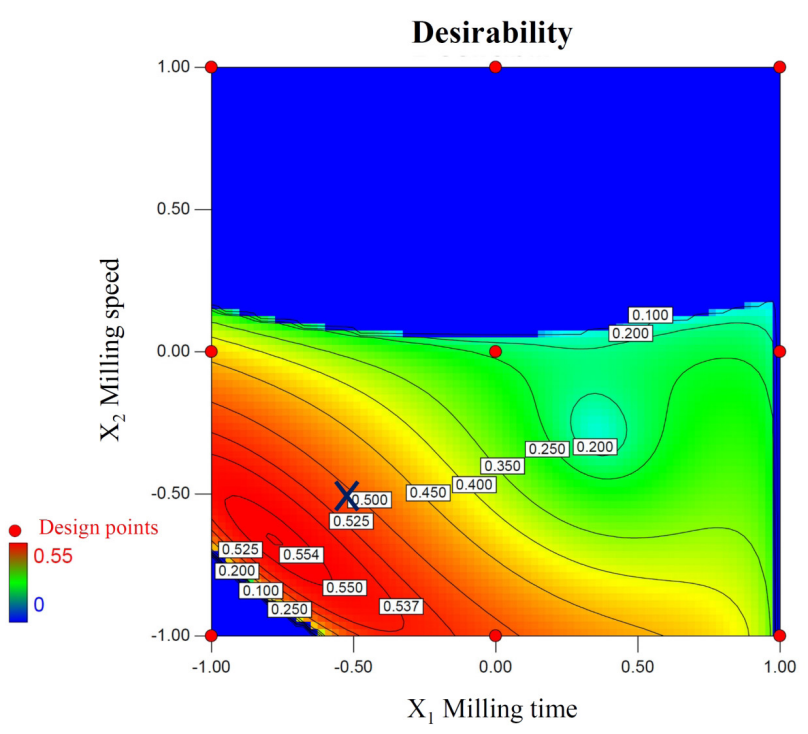

Fig. 3 Contour plot of the nanosuspension criteria by numerical optimization of desirability function, where $\mathrm{x}$ marks the chosen process parameters: $300 \mathrm{rpm}$ rotation speed, 30 minutes long operation, with $100 \mathrm{ml}$ of $X_{3}: d=0.1 \mathrm{~mm}$ sized zirconia milling beads applied 

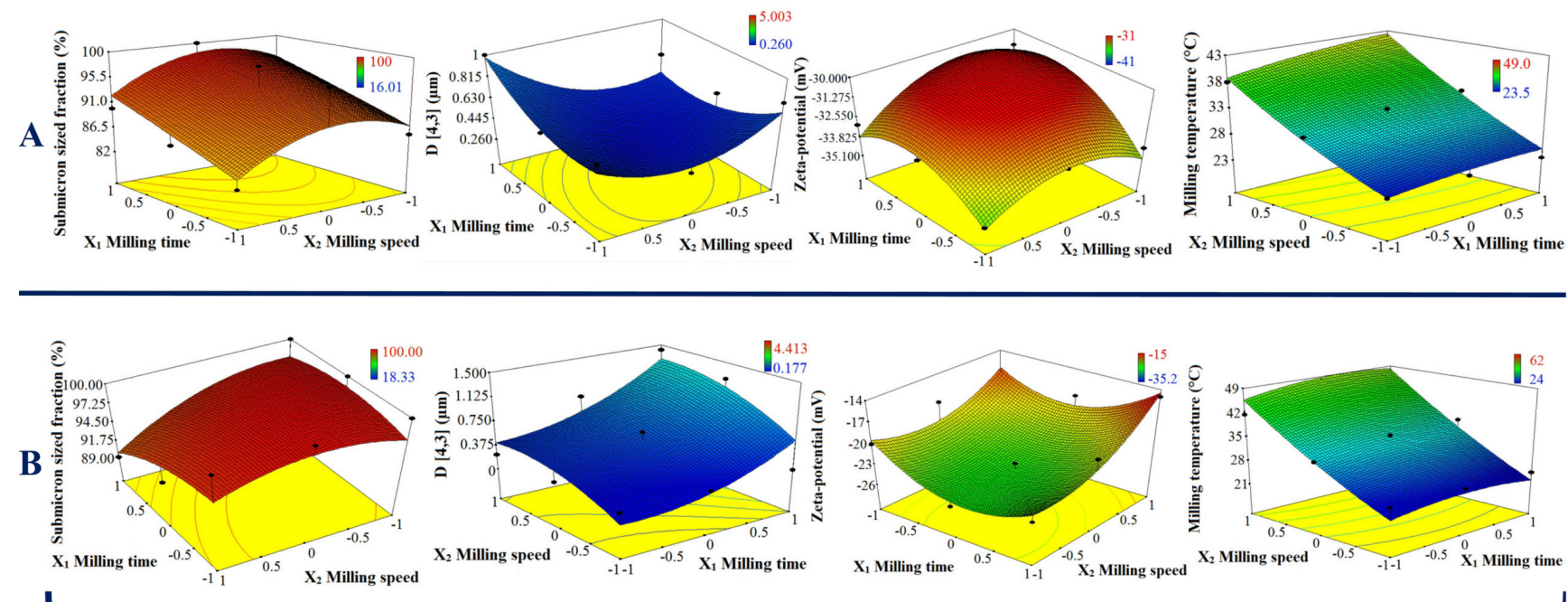

Aggregation due to increasing thermal stress (milling time $\uparrow$, milling speed $\uparrow$, volume of milling beads $\uparrow$ )

Fig. 4 Demonstration of the effect of milling time, milling speed on particle size distribution parameters and zeta-potential values of milled ABZ suspensions by 3-Dimensional response surface plots at A: $100 \mathrm{ml}$ and B: $200 \mathrm{ml}$ of milling beads applied, $n=5$, mean values \pm SDs, where $X_{3}: \mathrm{d}=0.1 \mathrm{~mm}$ sized zirconia beads

$400 \mathrm{rpm}$, at this rotation speed value submicron sized fraction was maximal $(100 \%)$ and volume weighted mean particle size $(D[4,3])$ was minimal $(0.192 \mu \mathrm{m})$, due to maximal specific surface area of ABZ nanocrystals, this is also the point, where mean zeta-potential value was maximal $(-30.5 \mathrm{mV})$. Above $400 \mathrm{rpm}$ rotation speed, aggregation due to increased thermal motion at higher milling temperature values $\left(36.0-39.0^{\circ} \mathrm{C}\right)$, can be observed, probably due to growing bead-bead collisions.

Milling trials with $d=0.3 \mathrm{~mm}$ and $d=1.0 \mathrm{~mm}$ sized beads showed less promising results compared to $d=0.1 \mathrm{~mm}$ beads, even tendencies were different, unlike $d=0.1 \mathrm{~mm}$ sized beads, prolonged, coarse operations yielded the best results considering volume-weighted mean particle sizes $1.600 \mu \mathrm{m}$ for $d=0.3 \mathrm{~mm}$ and $2.200 \mu \mathrm{m}$ for $\mathrm{d}=1.0 \mathrm{~mm}$ sized beads. Thus, prolonged operations are advisable for the development of ABZ nanosuspension by low energy wet bead milling method with the utilization of larger zirconia beads $(\mathrm{d}=0.3 \mathrm{~mm}, \mathrm{~d}=1.0 \mathrm{~mm})$ at higher milling speed values. In contrast application of smaller zirconia beads $(\mathrm{d}=0.1 \mathrm{~mm})$ are favored at lower to mediocre milling speeds, which yielded ABZ nanosuspension in a shorter process.

Utilization of $200 \mathrm{ml}$ applied volume of milling beads the same aggregation tendency can be registered at higher mechanical energy input for $\mathrm{d}=0.1 \mathrm{~mm}$ (Fig. 4) and even for $d=0.3$ beads, resulted in a significant milling temperature escalation from previously measured $39.0{ }^{\circ} \mathrm{C}$ to $49.9{ }^{\circ} \mathrm{C}$ for $\mathrm{d}=0.1 \mathrm{~mm}$ and $44.5^{\circ} \mathrm{C}$ for $\mathrm{d}=0.3 \mathrm{~mm}$ sized beads with higher zeta-potential values $>-26 \mathrm{mV}$ for $\mathrm{d}=0.1 \mathrm{~mm}$ and $>-33 \mathrm{mV}$ for $\mathrm{d}=0.3 \mathrm{~mm}$ observed compared to the mean zeta-potential value $(<-30.5 \mathrm{mV})$ at lower amount of beads applied previously. Preset nanosuspension criteria (see Subsection 2.5) excluded the application of higher amount of zirconia beads, due to higher zeta-potential values of milled ABZ suspensions.

Summarizing optimization results, we can report, that ideal loading consisted of $0.64 \%(\mathrm{w} / \mathrm{w}) \mathrm{ABZ}$, $20.60 \%(\mathrm{w} / \mathrm{w})$ surfactant solution, containing $0.50 \%(\mathrm{w} / \mathrm{w})$ Tween 80 mixed with $0.01 \%$ (v/v) dimethylpolysiloxane as antifoaming agent, $78.76 \%(\mathrm{w} / \mathrm{w}) \mathrm{d}=0.1 \mathrm{~mm}$ sized zirconia beads of the total mass loading at a batch size of $476.1498 \mathrm{~g}$, loaded in stainless steel container capacity of $500 \mathrm{ml}$. As for ideal chosen settings, milling speed was $300 \mathrm{rpm}$ with 30 minutes long 5:5 cyclic, milling operation. Milling temperature at the end of the process was $26.0^{\circ} \mathrm{C}$, showed a minimal $+8.0^{\circ} \mathrm{C}$ elevation compared to the temperature of starting surfactant solution.

The validation of responses predicted by the design model shall be performed in the final step. This is done by conducting confirmatory trials using RSM (response surface methodology) and the results are critically evaluated. Based on the trial results the optimal process parameters are set for manufacturing of the product [35, 67]. Validation trials were performed selecting the borderline points of the highlighted region of the contour plot (Fig. 3) including the point, which contributed to the optimized formulation 
parameters. Maximal relative standard deviation was calculated at verification trial No. 3., between actual and predicted mean span values (11.03\%), other noticeable differences were registered at verification trial No. 1., between actual and predicted mean milling temperature values (7.41\%), at verification trial No. 5., between actual and predicted mean size values $(6.48 \%)$ and at verification trial No. 6., between actual and predicted mean zeta-potential values $(7.38 \%$ ) (Table 5$)$. The fitted model demonstrated good predictions in overall and could be used for critical process parameter optimization.

\subsection{Comparison of the particle size distribution parameters of raw material $\mathrm{ABZ}$ powder and optimized ABZ nanosuspension}

Laser diffraction measurements have been performed to validate the mean particle size provided by the supplier $(>90$ $\%$ less, than $30 \mu \mathrm{m}$ ) of raw material albendazole powder after dispersing $3.00 \%(\mathrm{w} / \mathrm{w})$ ABZ to $0.5 \%$ (w/w) Tween 80 and $0.01 \%(\mathrm{v} / \mathrm{v})$ dimethylpolysiloxane aqueous-based surfactant solution at a mixing speed of $600 \mathrm{rpm}$, homogenization time 5 minutes on heatable magnetic stirrer MS-H-S10 (DLAB Instruments Ltd., China) at room temperature. Results demonstrated, that the $<30 \mu \mathrm{m}$ sized fraction was $88.82 \pm 0.561 \%$ and volume-weighted mean size $D$ $[4,3]$ of $28.787 \pm 3.0520 \mu \mathrm{m}$. Optimized, milled ABZ nanosuspension formulation yielded $\sim 145.39$ times reduction in mean size, $\sim 14.93$ times in mean polydispersity (span value) (Fig. 5), 18.47 times improvement in specific surface area, $\sim 9.55$ times boost in submicron sized fraction compared to unmilled ABZ surfactant dispersion. Freshly prepared end-product was also characterized by DLS and ELS methods as well, confirming the completion of predetermined nanosuspension criteria, with intensity-weighted mean size (Z AVG d) of $173.5 \pm 0.97 \mathrm{~nm}$, polydispersity index (PDI) of $0.175 \pm 0.0120$ and zeta-potential of $-38.2 \pm 0.83 \mathrm{mV}$.

\subsection{Comparison of the thermodynamic solubility values of starting material $\mathrm{ABZ}$ powder, Tween 80 dispersion and optimized, milled nanosuspension}

We have confirmed previous observations of Torrado et al. [5], that $\mathrm{ABZ}$ has $\mathrm{pH}$ dependent, poor water solubility, lowest value registered in medium at $\mathrm{pH}=6.80$, which was $7.3675 \pm 0.62803 \mu \mathrm{g} / \mathrm{ml}$, solubilization with $0.50 \%(\mathrm{w} / \mathrm{w})$ Tween 80 solution enhanced ABZ initial solubility to $25.5165 \pm 0.26791 \mu \mathrm{g} / \mathrm{ml}$ and gained a 2.46 - folds boost. Optimized, milled nanosuspension formula further improved performance and showed $62.5144 \pm 0.04845 \mu \mathrm{g} / \mathrm{ml}$ solubility, raised it 1.45 -folds compared to unmilled surfactant dispersion. In medium at $\mathrm{pH}=4.50$ the impact of mean solubility gains were slowly diminishing, initial solubility of raw ABZ powder $11.4917 \pm 0.15958 \mu \mathrm{g} / \mathrm{ml}$ was increased to $57.9846 \pm 2.71380 \mu \mathrm{g} / \mathrm{ml}$, which was a 4.05 -folds boost due to solubilization and optimized milling operation demonstrated $65.9163 \pm 0.05412 \mu \mathrm{g} / \mathrm{ml}$ value, showed a $13.68 \%$ boost compared to unmilled dispersion. Least gains in solubility were noticeable in medium at $\mathrm{pH}=1.20$, where initial solubility of ABZ was maximal $863.3964 \pm 3.72777 \mu \mathrm{g} / \mathrm{ml}$, which was elevated to $1010.5110 \pm 2.66921 \mu \mathrm{g} / \mathrm{ml}$, boosted by $17.04 \%$ due to solubilization and particle size reduction raised it further to $1269.7990 \pm 2.42509 \mu \mathrm{g} / \mathrm{ml}$, and gained a $25.66 \%$ boost compared to unmilled dispersion (Fig. 5).

\subsection{Comparison of the in-vitro dissolution profiles}

Dissolution rate constants have been calculated considering thermodynamic solubility values measured in

Table 5 Verification of the desirability optimization with milling process parameters and responses (mean values)

\begin{tabular}{|c|c|c|c|c|c|c|c|c|c|}
\hline $\begin{array}{l}\text { Verification } \\
\text { trial }\end{array}$ & $\begin{array}{c}X_{1} \\
\text { Milling } \\
\text { time (mins) }\end{array}$ & $\begin{array}{c}X_{2} \\
\text { Milling } \\
\text { speed }(\mathrm{rpm})\end{array}$ & $\begin{array}{c}X_{3} \\
\text { Size of } \\
\text { beads }(\mathrm{mm})\end{array}$ & $\begin{array}{l}\text { Point } \\
\text { prediction } \\
\text { method }\end{array}$ & $\begin{array}{c}Y_{1} \\
\text { Subm. sized } \\
\text { fraction }(\%)\end{array}$ & $\begin{array}{c}Y_{2} \\
D[4,3] \\
(\mu \mathrm{m})\end{array}$ & $\begin{array}{c}Y_{3} \\
\text { Span }\end{array}$ & $\begin{array}{c}Y_{4} \\
\text { Zeta-potential } \\
(\mathrm{mV})\end{array}$ & $\begin{array}{c}Y_{5} \\
\text { Milling } \\
\text { temperature }\left({ }^{\circ} \mathrm{C}\right)\end{array}$ \\
\hline \multirow{2}{*}{1} & \multirow{2}{*}{20} & \multirow{2}{*}{400} & \multirow{2}{*}{0.1} & Predicted & 93.35 & 0.453 & 2.331 & -33.07 & 37.76 \\
\hline & & & & Actual & 97.00 & 0.400 & 2.300 & -33.1 & 34.00 \\
\hline \multirow{2}{*}{2} & \multirow{2}{*}{40} & \multirow{2}{*}{200} & \multirow{2}{*}{0.1} & Predicted & 92.31 & 0.584 & 2.100 & -31.19 & 25.81 \\
\hline & & & & Actual & 90.21 & 0.6 & 2.100 & -31.5 & 24.00 \\
\hline \multirow{2}{*}{3} & \multirow{2}{*}{40} & \multirow{2}{*}{400} & \multirow{2}{*}{0.1} & Predicted & 94.49 & 0.304 & 2.252 & -30.31 & 39.15 \\
\hline & & & & Actual & 98 & 0.260 & 2.180 & -31.30 & 37.00 \\
\hline \multirow{2}{*}{4} & \multirow{2}{*}{60} & \multirow{2}{*}{400} & \multirow{2}{*}{0.1} & Predicted & 98.31 & 0.254 & 2.175 & -30.92 & 37.07 \\
\hline & & & & Actual & 100 & 0.262 & 2.150 & -31.30 & 37.00 \\
\hline \multirow{2}{*}{5} & \multirow{2}{*}{60} & \multirow{2}{*}{200} & \multirow{2}{*}{0.1} & Predicted & 96.09 & 0.625 & 1.962 & -31.32 & 23.13 \\
\hline & & & & Actual & 93.69 & 0.685 & 2.000 & -31.00 & 24.00 \\
\hline \multirow{2}{*}{6} & \multirow{2}{*}{30} & \multirow{2}{*}{300} & \multirow{2}{*}{0.1} & Predicted & 99.41 & 0.205 & 0.900 & -34.41 & 28.00 \\
\hline & & & & Actual & 100 & 0.189 & 0.864 & -38.20 & 26.00 \\
\hline
\end{tabular}



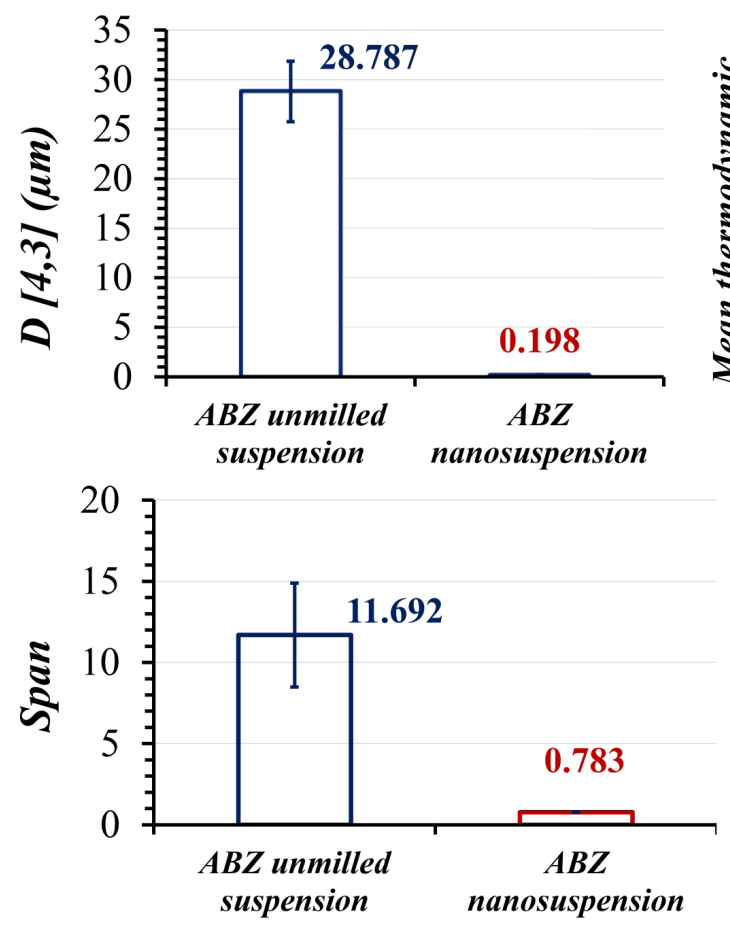
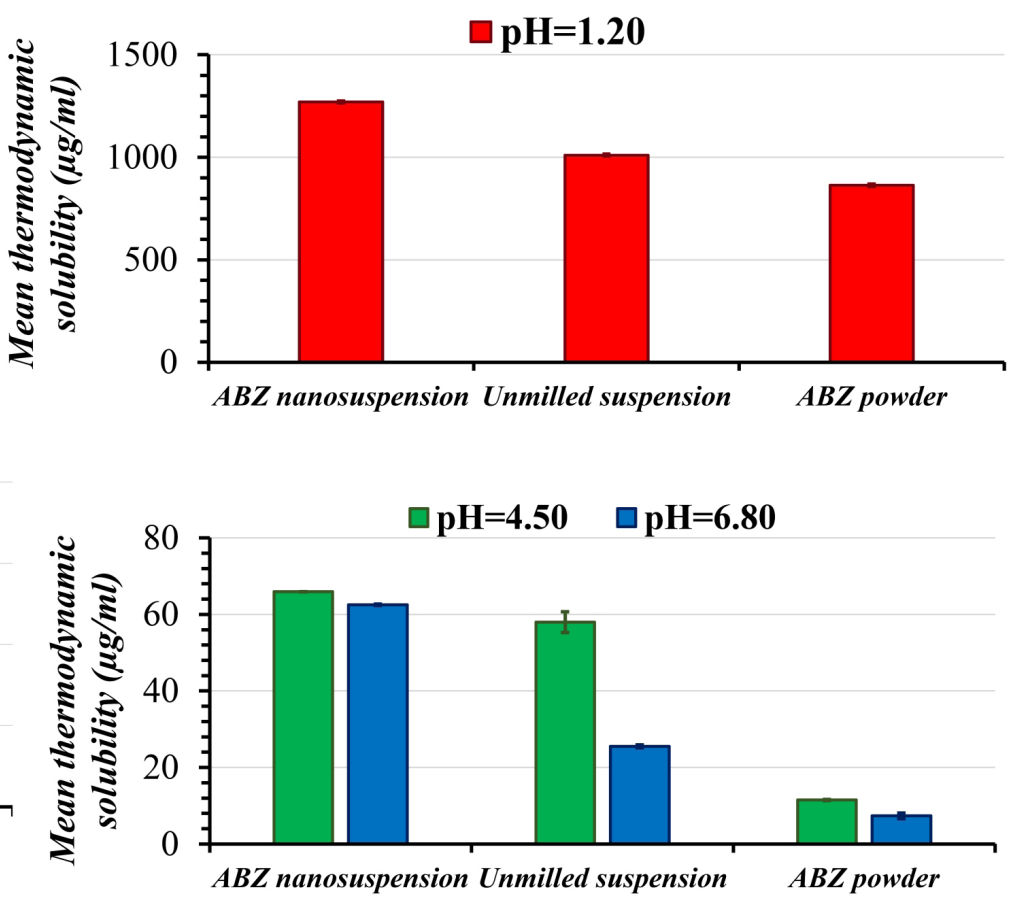

Fig. 5 Impact of volume weighted mean particle size $(D[4,3])$ on mean thermodynamic solubility values of $\mathrm{ABZ}(\mathrm{mean} \pm \mathrm{SD}, \mathrm{n}=3)$

appropriate media, lag times and shape parameter values with Weibull model fitting on measured dissolution points (Table 6 and Fig. 6).

\subsection{Drug content and impact of the washing of beads} and dilution on particle size distribution parameters and zeta-potential values of milled $\mathrm{ABZ}$ suspensions By simply pouring the optimized ABZ nanosuspension on sieve and separating it from beads, mean ABZ yield was low $60.53 \pm 3.485 \%$ (Table 7). It contained $200.000 \pm 0.3438$ $\mathrm{mg}$ of ABZ in $5.471 \mathrm{~cm}^{3}$ volume. Washing the beads after milling operations with different amounts of $0.50 \%(w / w)$ Tween 80 and $0.01 \%$ (v/v) dimethylpolysiloxane containing aqueous-based surfactant solutions have demonstrated, that increasing amount of Tween 80 added to milled suspensions slightly increased particle size distributions parameters and decreased zeta-potential values, while submicron sized fractions were permanent, which can be explained by the steric stabilization effect of Tween 80 . Best case scenario was the additional $33.33 \%$ (w/w) surfactant solution of total mass loading added to milled ABZ suspension, where reasonable ABZ yield $83.05 \pm 2.783 \%$ was achieved, in a relatively low mean dose of $7.094 \mathrm{~cm}^{3}$. This diluted ABZ nanosuspension was then subjected to short-term physical stability evaluations.

\subsection{Short-term physical stability evaluations of optimized ABZ nanosuspension}

Short-term physical stability of optimized formula was characterized by recording particle size distribution parameters with both LD and DLS methods at predetermined time points (Fig. 7). The volume-weighted mean particle size $(D[4,3])$ and intensity-weighted mean particle size ( $\mathrm{Z}$ AVG $\mathrm{d}$ ) values were the most sensitive to aggregation. Results demonstrated, that refrigerated conditions were more suitable for storage of ABZ nanosuspensions,

Table 6 Influence of particle size reduction and solubilization of ABZ on fitted dissolution rate constants $(\mathrm{k}), \mathrm{n}=3$, mean values \pm SDs

\begin{tabular}{|c|c|c|c|c|c|c|c|c|c|}
\hline \multirow{2}{*}{$\begin{array}{l}\text { Sample } \\
\text { Medium }\end{array}$} & \multicolumn{3}{|c|}{ ABZ powder } & \multicolumn{3}{|c|}{ ABZ Tween 80 dispersion } & \multicolumn{3}{|c|}{ Optimized ABZ nanosuspension } \\
\hline & $t_{0}(\min )$ & $\begin{array}{c}k(\min )^{-1} \pm \\
\mathrm{SD}\end{array}$ & $R^{2}$ & $t_{0}(\min )$ & $\begin{array}{c}k(\min )^{-1} \pm \\
\mathrm{SD}\end{array}$ & $R^{2}$ & $t_{0}(\min )$ & $\begin{array}{c}k(\min )^{-1} \pm \\
\mathrm{SD}\end{array}$ & $R^{2}$ \\
\hline $\mathrm{pH}=1.20$ & 0 & $\begin{array}{c}0.0309 \pm \\
0.00336\end{array}$ & 0.9880 & 0 & $\begin{array}{c}0.0911 \pm \\
0.00910\end{array}$ & 0.9806 & 0 & $\begin{array}{l}1.3207 \pm \\
0.02691\end{array}$ & 0.9435 \\
\hline $\mathrm{pH}=4.50$ & 15.0 & $\begin{array}{l}0.0102 \pm \\
0.00048\end{array}$ & 0.9719 & 15.0 & $\begin{array}{l}0.0321 \pm \\
0.00159\end{array}$ & 0.9878 & 0 & $\begin{array}{c}0.4249 \pm \\
0.00084\end{array}$ & 0.9368 \\
\hline $\mathrm{pH}=6.80$ & 30.0 & $\begin{array}{c}0.0138 \pm \\
0.00158\end{array}$ & 0.9962 & 4.0 & $\begin{array}{l}0.0170 \pm \\
0.00047\end{array}$ & 0.9740 & 0 & $\begin{array}{c}0.2722 \pm \\
0.01384\end{array}$ & 0.9523 \\
\hline
\end{tabular}




\section{$\mathbf{p H}=1.2$}

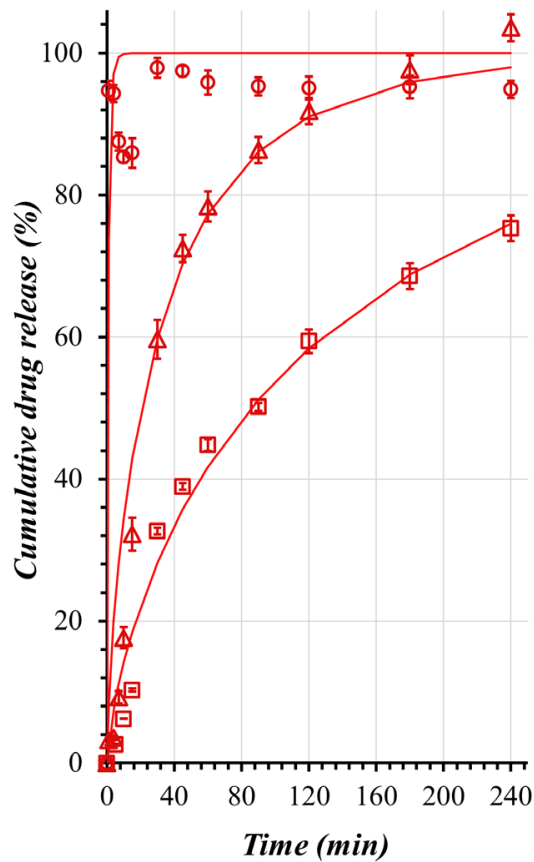

$\mathrm{pH}=4.5$

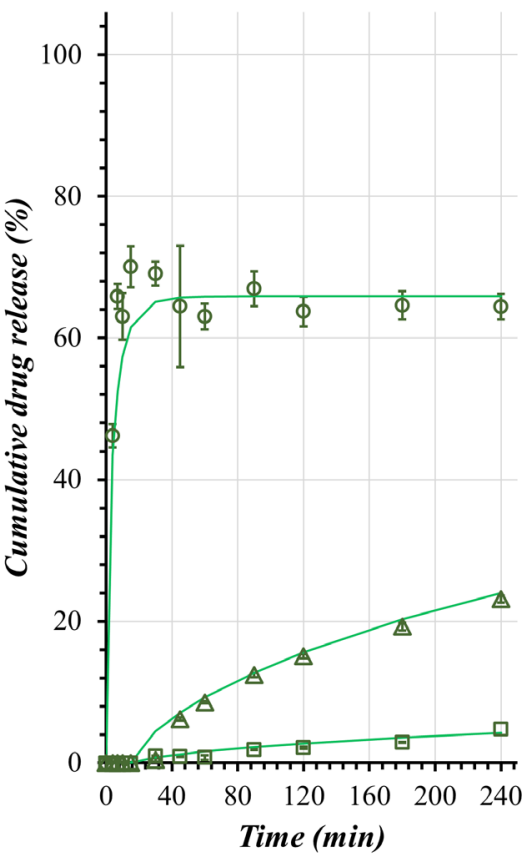

$\mathrm{pH}=6.8$

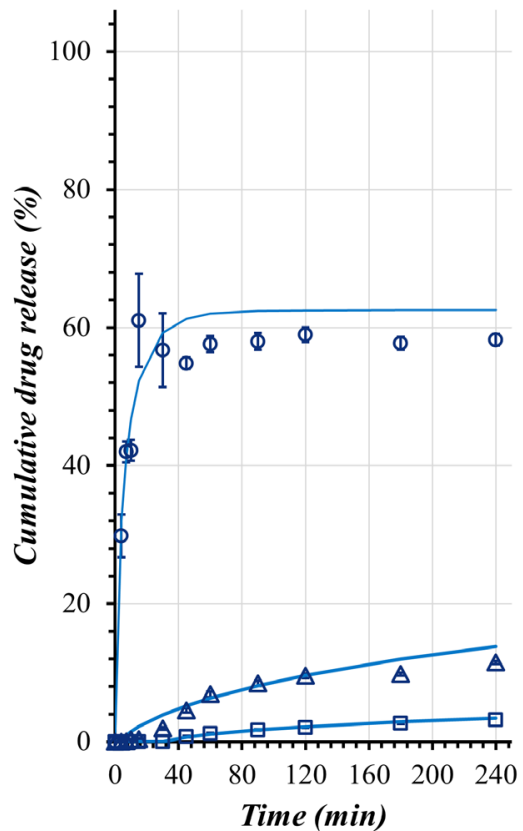

Fig. 6 Comparison of the fitted in-vitro dissolution profiles of optimized, milled ABZ nanosuspension ( $(\circ)$, unmilled surfactant dispersion $(\Delta)$ and ABZ powder $(\square)$ in various, aqueous based buffer solutions $(\mathrm{pH}=1.2, \mathrm{pH}=4.5, \mathrm{pH}=6.8), n=3$, mean values $\pm \mathrm{SDs}$

micro sized aggregates have been detected by LD at 56 days of storage, under refrigerated conditions. At room temperature however, micro sized aggregates have been observed much sooner at 28 days of storage.

\subsection{Diffraction pattern comparison of raw $\mathrm{ABZ}$ powder and processed in dried, milled suspensions}

Our experimental PXRD results in agreement with previous ones by Chattah et al. [10] and Pranzo et al. [13] have demonstrated, that raw $\mathrm{ABZ}$ powder consisted of both polymorphic forms of ABZ, Form I and Form II (Fig. 8). Most intensive Form I main, characteristic peaks can be identified at positions of $6.9^{\circ}, 11.3^{\circ}, 11.6^{\circ}, 17.9^{\circ}, 24.4^{\circ}$, and $27.2^{\circ}\left(2^{\circ} \theta\right)$. Form II main peaks were also consistent with the literature located at $7.3^{\circ}, 10.7^{\circ}, 14.6^{\circ}, 18.1^{\circ}, 24.7^{\circ}$, $25.6^{\circ}$ and $30.5^{\circ}\left(2^{\circ} \theta\right)$ positions. It seemed drying had no effect on ABZ polymorphy, dried, optimized, milled ABZ nanosuspension also contained both forms. We've reached higher milling temperature values at higher amount of milling beads applied $(200 \mathrm{ml})$, especially with the utilization of $d=0.3 \mathrm{~mm}$ sized ones during coarse milling programs (involving $600 \mathrm{rpm}$ milling speeds and at least 60 minutes long operations). For demonstration of extreme conditions, a 180 minute long operation was tested in a

Table 7 Influence of beads washing and dilution on final ABZ yield, particle size distribution parameters, zeta-potential values and dose of optimized, milled ABZ nanosuspension, $n=3$, mean values \pm SDs

\begin{tabular}{|c|c|c|c|c|c|}
\hline \multicolumn{6}{|c|}{ Washing with additional optimal surfactant solutions of total mass loading ( $\% \mathrm{w} / \mathrm{w})$} \\
\hline Parameter & $\begin{array}{l}\text { Optimized milled } \\
\text { nanosuspension }\end{array}$ & 16.67 & $2 x^{*} 16.67$ & 33.33 & $2 * 33.33$ \\
\hline Yield (\%) & $60.53 \pm 3.485$ & $70.90 \pm 3.245$ & $86.00 \pm 2.850$ & $83.05 \pm 2.783$ & $86.00 \pm 2.670$ \\
\hline Z AVG d (nm) & $173.500 \pm 0.9702$ & $183.475 \pm 0.1732$ & $174.300 \pm 1.4450$ & $182.200 \pm 1.3130$ & $178.800 \pm 2.6990$ \\
\hline PDI & $0.175 \pm 0.0120$ & $0.191 \pm 0.0080$ & $0.183 \pm 0.0100$ & $0.187 \pm 0.0160$ & $0.190 \pm 0.0080$ \\
\hline Zeta-potential (mV) & $-38.20 \pm 0.830$ & $-38.13 \pm 0.928$ & $-37.60 \pm 0.576$ & $-51.90 \pm 0.465$ & $-41.80 \pm 0.907$ \\
\hline $\mathrm{D}[4,3](\mu \mathrm{m})$ & $0.189 \pm 0.0022$ & $0.190 \pm 0.0010$ & $0.193 \pm 0.0015$ & $0.194 \pm 0.0005$ & $0.204 \pm 0.0004$ \\
\hline Span & $0.864 \pm 0.0198$ & $0.977 \pm 0.0022$ & $0.902 \pm 0.0016$ & $0.923 \pm 0.0041$ & $1.006 \pm 0.0093$ \\
\hline $\begin{array}{l}\text { Dose }(200 \mathrm{mg}) \text { in } \\
\text { volume }(\mathrm{ml})\end{array}$ & $5.471 \pm 0.0094$ & $6.373 \pm 0.1378$ & $6.851 \pm 0.0671$ & $7.094 \pm 0.0238$ & $7.978 \pm 0.1247$ \\
\hline
\end{tabular}



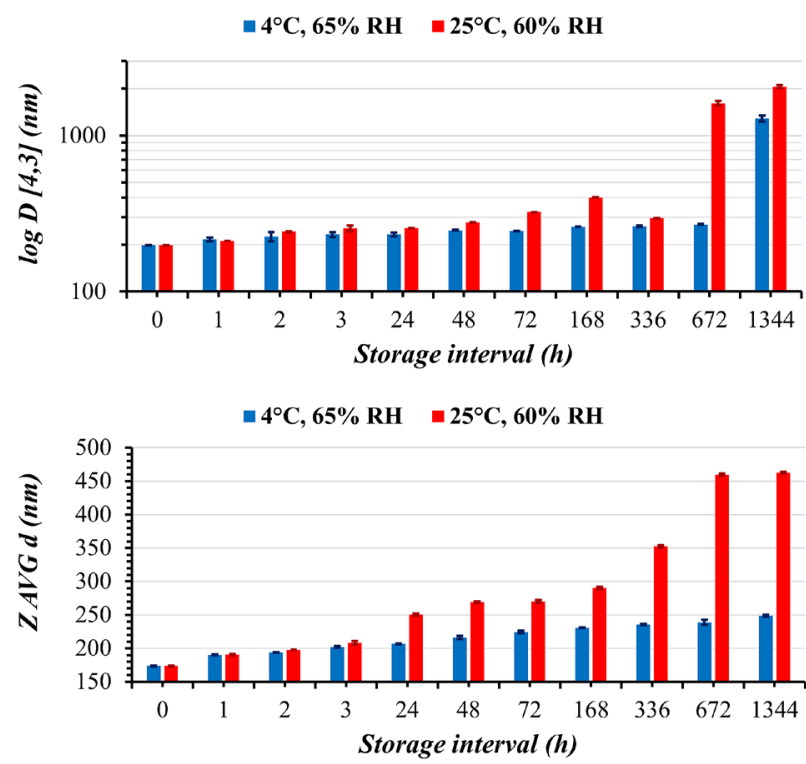

Fig. 7 Influence of storage conditions and time on mean particle size values of optimized, milled ABZ nanosuspensions measured by LD and DLS methods, $n=3$, mean values \pm SDs

stainless steel container with capacity of $500 \mathrm{ml}$ among previously described settings, without complete conversion of Form I to Form II registered. So, $50{ }^{\circ} \mathrm{C}$ milling temperature during a 180 minute long session was not enough for the detection of only Form II characteristic peaks. By switching container sizes from $500 \mathrm{ml}$ to 50 $\mathrm{ml}$ and therefore, increasing thermal inertia (lowering the total volume of cooling surfactant solution present in the container) milling programs involving various process times ( 30 minutes, 60 minutes, 180 minutes) were compared. As expected, milling temperature values have massively increased to $60.0^{\circ} \mathrm{C}, 65^{\circ} \mathrm{C}$, and $72{ }^{\circ} \mathrm{C}$ respectively, which was enough for triggering total conversion of ABZ Form I to Form II in a short amount of time (30 minutes). Conversion was noticeable from the shifted colors of milled suspensions from pale white to brown.

\section{Conclusions}

Based on QbD approach, ABZ containing nanosuspension was prepared with top-down low energy planetary bead milling. Optimized formula showed less, than $200 \mathrm{~nm}$ mean size with narrow distribution (PDI < 0.200), which can easily compete with the results of newly developed 'bottom-up' nanoparticle production techniques. Statistical results of optimization suggested the selection of $\mathrm{d}=0.1 \mathrm{~mm}$ sized zirconia beads in lower $(100 \mathrm{ml})$ volume, at low to mediocre milling speed intervals $(200-434 \mathrm{rpm})$ up to a maximum of 40 minutes long milling operations.

The utilization of ABZ nanocrystals proved to increase thermodynamic solubility values in all tested media, which was most efficient, where initial solubility was minimal. On the contrary improvement of dissolution rate values were the most prominent, where initial solubility was maximal. No lag time values were observed in the

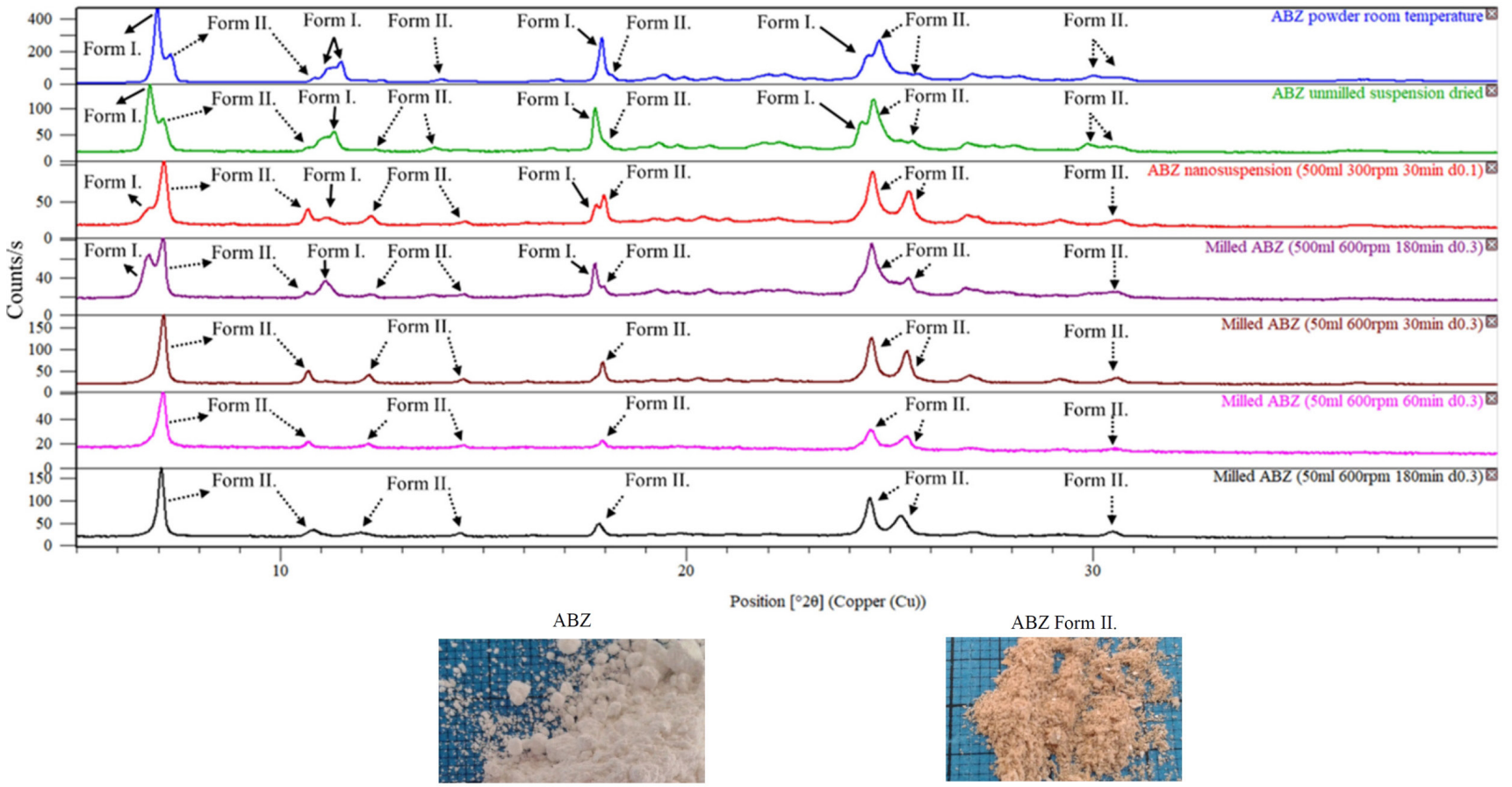

Fig. 8 Comparison of the diffraction patterns of raw material ABZ powder and ABZ processed in dried, milled suspensions 
dissolution kinetics of the nanosuspension in comparison with the unmilled and raw powder samples.

Washing the beads after milling with $33.33 \%(\mathrm{w} / \mathrm{w})$ of total mass loading with surface active agent solutions and mixed with ABZ nanosuspensions have demonstrated reasonable $\mathrm{ABZ}$ yield (83.05\%), in a relatively low mean dose of $7.094 \mathrm{~cm}^{3}$. Without solidification micrometer sized aggregates have appeared at 28 days of storage at room temperature and at 56 days at refrigerated conditions.

PXRD studies revealed, that the optimized product contained both polymorphs, so there was no recrystallization due to careful evaluation of loading composition and milling parameters. Although extreme milling conditions have been identified, where undesirable full polymorphic conversion of ABZ from Form I to Form II has been realized. Critical conditions included the application of $\mathrm{d}=0.3$ $\mathrm{mm}$ sized zirconia beads, in high volume $(200 \mathrm{ml})$, loaded in a smaller milling container $(50 \mathrm{ml})$ and with the utilization of coarse milling programs involving $600 \mathrm{rpm}$ rotation speeds and 30-180 minutes long operations.

\section{Abbreviations}

1 ABZ - Albendazole

2 PXRD - Powder X-Ray Diffractometry

3 Log P - Lipophilicity, the octanol-water partition coefficient of a molecule

\section{References}

[1] Lipinski, C. A. "Poor Aqueous Solubility - An Industry Wide Problem in Drug Discovery", American Pharmaceutical Review, 5(3), pp 82-85, 2002.

[2] Campbell, W. C. "Benzimidazoles: Veterinary uses", Parasitology Today, 6(4), pp. 130-133, 1990.

https://doi.org/10.1016/0169-4758(90)90231-R

[3] McKellar, Q. A., Scott, E. W. "The benzimidazole anthelmintic agents - a review", Journal of Veterinary Pharmacology and Therapeutics, 13(3), pp. 223-247, 1990.

https://doi.org/10.1111/j.1365-2885.1990.tb00773.x

[4] GlaxoSmithKline Pharmaceuticals Limited "ZEN/PI/IN/2018/02 Zentel Albendazole Tablets IP / albendazole Oral Suspension IP", [pdf] GlaxoSmithKline plc., India. Available at: https://indiapharma.gsk.com/media/701423/zentel.pdf [Accessed: 19 July 2019]

[5] Torrado, S., Torrado, S., Cadorniga, R., Torrado, J. J. "Formulation parameters of albendazole solution", International Journal of Pharmaceutics, 140(1), pp. 45-50, 1996.

https://doi.org/10.1016/0378-5173(96)04545-0

[6] Mottier, M. L., Alvarez, L. I., Pis, M. A., Lanusse, C. E. "Transtegumental diffusion of benzimidazole anthelmintics into Moniezia benedeni: correlation with their octanol-water partition coefficients", Experimental Parasitology, 103(1-2), pp. 1-7, 2003.
4 BCS - Biopharmaceutical Classification System

5 RES - Reticuloendothelial System

6 DOE - Design of Experiments

7 QbD - Quality by Design

8 OVAT - One variable at a time

9 WSSM - Wet stirred media milling

$10 \mathrm{HPH}$ - High pressure homogenization

$11 D[4,3]$ - Volume-weighted mean particle size (De Brouckere Mean Diameter)

12 AF - Antifoaming Agent

13 SLS - Sodium Laurylsulphate

14 LD - Laser Diffraction

15 PSC or DLS - Photon Correlation Spectroscopy or Dynamic Light Scattering

16 NIBS - Non-Invasive-Backscattering

17 PSD - Particle Size Distribution

18 Span - Polydispersity, width of a particle size distribution

19 Z AVG d - Intensity-weighted mean particle size

20 PDI - Polydispersity index

21 ELS - Electrostatic Light Scattering

22 PES - Polyether sulfonate

23 RH - Relative Humidity

[7] Dahan, A., Miller, J. M., Amidon, G. L. "Prediction of Solubility and Permeability Class Membership: Provisional BCS Classification of the World' s Top Oral Drugs", The AAPS Journal, 11(4), pp. 740-746, 2009.

https://doi.org/10.1208/s12248-009-9144-X

[8] Lödenberg, R., Amidon, G. L. "Modern bioavailability, bioequivalence and biopharmaceutics classification system. New scientific approaches to international regulatory standards", European Journal of Pharmaceutics and Biopharmaceutics, 50(1), pp. 3-12, 2000. https://doi.org/10.1016/S0939-6411(00)00091-6

[9] Fülöp, V., Jakab, G., Bozó, T., Tóth, B., Endrésik, D., Balogh, E., Kellermayer, M., Antal, I. "Study on the dissolution improvement of albendazole using reconstitutable dry nanosuspension formulation", European Journal of Pharmaceutical Sciences, 123, pp. 70-78, 2018. https://doi.org/10.1016/j.ejps.2018.07.027

[10] Chattah, A. K., Zhang, R., Mroue, K. H., Pfund, L. Y., Longhi, M. R., Ramamoorthy, A., Garnero, C. "Investigating Albendazole Desmotropes by Solid-State NMR Spectroscopy", Molecular Pharmaceutics, 12(3), pp. 731-741, 2015. https://doi.org/10.1021/mp500539g

[11] Galia, E., Horton, J., Dressman, J. B. "Albendazole Generics - A Comparative In Vitro Study", Pharmaceutical Research, 16(12), pp. 1871-1875, 1999.

https://doi.org/10.1023/A:1018907527253 
[12] Wen, H., New, R. R. C., Muhmut, M., Wang, J. H., Wang, Y. H., Zhang, J. H., Shao, Y. M., Craig, P. S. "Pharmacology and efficacy of liposome-entrapped albendazole in experimental secondary alveolar echinococcosis and effect of co-administratration with cimetidine", Parasitology, 113(2), pp. 111-121, 1996. https://doi.org/10.1017/s003118200006635x

[13] Pranzo, M. B., Cruickshank, D., Coruzzi, M., Caira, M. R., Bettini, R. "Enantiotropically Related Albendazole Polymorphs", 99(9), pp. 3731-3742, 2010. https://doi.org/10.1002/jps.22072

[14] Prabhakar, C., Bala Krishna, K. "A review on nanosuspensions in drug delivery", International Journal of Pharma and Bio Sciences, 2(1), pp. 549-558, 2011.

[15] Bi, Y., Liu, J., Wang, J., Hao, J., Li, F., Wang, T., Sun, H. W., Guo, F. "Particle size control and the interactions between drug and stabilizers in an amorphous nanosuspension system", Journal of Drug Delivery Science and Technology, 29, pp. 167-172, 2015. https://doi.org/10.1016/j.jddst.2015.07.012

[16] Chingunpituk, J. "Nanosuspension Technology for Drug Delivery", Walailak Journal of Science and Technology, 4(2) pp. 139-153, 2007. [online] Available at: http://wjst.wu.ac.th/index.php/wjst/ article/view/94 [Accessed: 19 July 2019]

[17] Junyaprasert, V. B., Morakul, B. "Nanocrystals for enhancement of oral bioavailability of poorly water-soluble drugs", Asian Journal of Pharmaceutical Sciences, 10(1), pp. 13-23, 2015. https://doi.org/10.1016/j.ajps.2014.08.005

[18] Rabinow, B. E. "Nanosuspensions in drug delivery", Nature Reviews Drug Discovery, 3(9), pp. 785-796, 2004. https://doi.org/10.1038/nrd1494

[19] Ibrahim, H. M., Ismail, H. R., Lila, A. E. A. "Formulation and Optimization of Ocular Poly-D, L-lactic Acid Nano Drug Delivery System of Amphotericin-B Using Box Behnken Design", International Journal of Pharmacy and Pharmaceutical Sciences, 4(2), pp. 342-349, 2012.

[20] Yadollahi, R., Vasilev, K., Simovic, S. "Nanosuspension Technologies for Delivery of Poorly Soluble Drugs", Journal of Nanomaterials, 2015, Article ID: 216375, 2015.

https://doi.org/10.1155/2015/216375

[21] Mitragotri, S., Burke, P. A., Langer, R. "Overcoming the challenges in administering biopharmaceuticals: formulation and delivery strategies", Nature Reviews Drug Discovery, 13(9), pp. 655-672, 2014.

https://doi.org/10.1038/nrd4363

[22] Müller, R. H., Gohla, S., Keck, C. M. "State of the art of nanocrystals - Special features, production, nanotoxicology aspects and intracellular delivery", European Journal of Pharmaceutics and Biopharmaceutics, 78(1), pp. 1-9, 2011. https://doi.org/10.1016/j.ejpb.2011.01.007

[23] Hu, L., Yang, C., Kong, D., Hu, Q., Gao, N., Zhai, F. "Development of a long-acting intramuscularly injectable formulation with nanosuspension of andrographolide", Journal of Drug Delivery Science and Technology, 35, pp. 327-332, 2016. https://doi.org/10.1016/j.jddst.2016.08.008

[24] Toziopoulou, F., Malamatari, M., Nikolakakis, I., Kachrimanis, K. "Production of aprepitant nanocrystals by wet media milling and subsequent solidification", International Journal of Pharmaceutics, 533(2), pp. 324-334, 2017.

https://doi.org/10.1016/j.ijpharm.2017.02.065
[25] Wei, Q., Keck, C. M., Müller, R. H. "Solidification of hesperidin nanosuspension by spray drying optimized by design of experiment (DoE)", Drug Development and Industrial Pharmacy, 44(1), pp. 1-12, 2018.

https://doi.org/10.1080/03639045.2017.1285309

[26] Ma, Y. Q., Zhang, Z. Z., Li, G., Zhang, J., Xiao, H. Y., Li, X. F. "Solidification drug nanosuspensions into nanocrystals by freeze-drying: a case study with ursodeoxycholic acid", Pharmaceutical Development and Technology, 21(2), pp. 180-188, 2016.

https://doi.org/10.3109/10837450.2014.982822

[27] Han, J., Wang, X., Wang, J., Wang, L., Chen, L., Li, J., Li, W. "Quality-by-Design approach to the fluid-bed coating of ginkgo lactone nanosuspensions", RSC Advances, 8(39), pp. 22136-22145, 2018.

https://doi.org/10.1039/c8ra03288b

[28] Anup, N., Thakkar, S., Misra, M. "Formulation of olanzapine nanosuspension based orally disintegrating tablets (ODT); comparative evaluation of lyophilization and electrospraying process as solidification techniques", Advanced Powder Technology, 29(8), pp. 1913-1924, 2018. https://doi.org/10.1016/j.apt.2018.05.003

[29] Gajera, B. Y., Shah, D. A., Dave, R. H. "Investigating a Novel Hot Melt Extrusion-Based Drying Technique to Solidify an Amorphous Nanosuspension Using Design of Experiment Methodology", AAPS PharmSciTech, 19(8), pp. 3778-3790, 2018. https://doi.org/10.1208/s12249-018-1189-7

[30] Kumar, M. P., Rao, Y. M., Apte, S. "Improved Bioavailability of Albendazole Following Oral Administration of Nanosuspension in Rats", Current Nanoscience, 3(2), pp. 191-194, 2007. https://doi.org/10.2174/157341307780619224

[31] Li, W., Quan, P., Zhang, Y., Cheng, J., Liu, J., Cun, D., Xiang, R., Fang, L. "Influence of drug physicochemical properties on absorption of water insoluble drug nanosuspensions", International Journal of Pharmaceutics, 460(1-2), pp. 13-23, 2014. https://doi.org/10.1016/j.jpharm.2013.10.038

[32] Rao, Y.M., Kumar, M. P., Apte, S. "Formulation of Nanosuspensions of Albendazole for Oral Administration", Current Nanoscience, 4(1), pp. 53-58, 2008. https://doi.org/10.2174/157341308783591807

[33] Liu, Y., Wang, X. Q., Ren, W. X., Chen, Y. L., Yu, Y., Zhang, J. K., Bawudong, D., Gu, J. P., Xu, X. D., Zhang, X. N. "Novel albendazole-chitosan nanoparticles for intestinal absorption enhancement and hepatic targeting improvement in rats", Journal of Biomedical Materials Research: Part B Applied Biomaterials, 101B(6), pp. $998-1005,2013$. https://doi.org/10.1002/jbm.b.32908

[34] Torabi, N., Dobakhti, F., Haniloo, A. "Albendazole and Praziquantel Chitosan Nanoparticles: Preparation, Characterization, and In Vitro Release Study", Iranian Journal of Science and Technology, Transactions A: Science, 42(3), pp. 1269-1275, 2018. https://doi.org/10.1007/s40995-017-0150-z

[35] Nekkanti, V., Marwah, A., Pillai, R. "Media Milling Process Optimization for Manufacture of Drug Nanoparticles Using Design of Experiments (DOE)", Drug Development and Industrial Pharmacy, 41(1), pp. 124-130, 2015. https://doi.org/10.3109/03639045.2013.850709 
[36] StatEase "Desirability Function", [online] Available at: https:// www.statease.com/docs/v11/contents/optimization/desirability-function/ [Accessed: 01 October 2019]

[37] U.S. Department of Health and Human Services, Food and Drug Administration "Guidance for Industry Quality Systems Approach to Pharmaceutical CGMP Regulations", [pdf] U.S. Department of Health and Human Services, Food and Drug Administration, Silver Spring, MD, USA, 2006. Available at: https://www.fda.gov/ media/71023/download [Accessed: 05 October 2019]

[38] Hao, J., Gao, Y., Zhao, J., Zhang, J., Li, Q., Zhao, Z., Liu, J. "Preparation and Optimization of Resveratrol Nanosuspensions by Antisolvent Precipitation Using Box-Behnken Design", AAPS PharmSciTech, 16(1), pp. 118-128, 2015. https://doi.org/10.1208/s12249-014-0211-y

[39] Fernandes, A. R., Ferreira, N. R., Fangueiro, J. F., Santos, A. C., Veiga, F. J., Cabral, C., Silva, A. M., Souto, E. B. "Ibuprofen nanocrystals developed by $2^{2}$ factorial design experiment: A new approach for poorly water-soluble drugs", Saudi Pharmaceutical Journal, 25(8), pp. 1117-1124, 2017. https://doi.org/10.1016/j.jsps.2017.07.004

[40] Mishra, B., Sahoo, J., Dixit, P. K. "Formulation and process optimization of naproxen nanosuspensions stabilized by hydroxy propyl methyl cellulose", Carbohydrate Polymers, 127, pp. 300-308, 2015. https://doi.org/10.1016/j.carbpol.2015.03.077

[41] Mishra, B., Sahoo, J., Dixit, P. K. "Enhanced bioavailability of cinnarizine nanosuspensions by particle size engineering: Optimization and physicochemical investigations", Materials Science and Engineering: C, 63, pp. 62-69, 2016. https://doi.org/10.1016/j.msec.2016.02.046

[42] Medarević, D., Djuriš, J., Ibrić, S., Mitrić, M., Kachrimanis, K. "Optimization of formulation and process parameters for the production of carvedilol nanosuspension by wet media milling", International Journal of Pharmaceutics, 540(1-2) pp. 150-161, 2018. https://doi.org/10.1016/j.ijpharm.2018.02.011

[43] Li, M., Azad, M., Davé, R., Bilgili, E. "Nanomilling of Drugs for Bioavailability Enhancement: A Holistic Formulation-Process Perspective", Pharmaceutics, 8(2), Article Number: 17, 2016. https://doi.org/10.3390/pharmaceutics8020017

[44] Li, M., Alvarez, P., Bilgili, E. "A microhydrodynamic rationale for selection of bead size in preparation of drug nanosuspensions via wet stirred media milling", International Journal of Pharmaceutics, 524(1-2), pp. 178-192, 2017.

https://doi.org/10.1016/j.ijpharm.2017.04.001

[45] Feng, T., Pinal, R., Carvajal, M. T. "Process Induced Disorder in Crystalline Materials: Differentiating Defective Crystals from the Amorphous Form of Griseofulvin", Journal of Pharmaceutical Sciences, 97(8), pp. 3207-3221, 2008.

https://doi.org/10.1002/jps.21219

[46] Bouvart, N., Palix, R. M., Arkhipov, S. G., Tumanov, I. A., Michalchuk, A. A. L., Boldyreva, E. V. "Polymorphism of chlorpropamide on liquid-assisted mechanical treatment: choice of liquid and type of mechanical treatment matter", CrystEngComm, 20(13), pp. 1797-1803, 2018.

https://doi.org/10.1039/c7ce02221b
[47] Belenguer, A. M., Lampronti, G. I., Cruz-Cabeza, A. J., Hunter, C. A., Sanders, J. K. M. "Solvation and surface effects on polymorph stabilities at the nanoscale", Chemical Science, 7(11), pp. $6617-6627,2016$. https://doi.org/10.1039/c6sc03457h

[48] Fischer, F., Heidrich, A., Greiser, S., Benemann, S., Rademann, K., Emmerling, F. "Polymorphism of Mechanochemically Synthesized Cocrystals: A Case Study", Crystal Growth and Design, 16(3), pp. 1701-1707, 2016. https://doi.org/10.1021/acs.cgd.5b01776

[49] Hasa, D., Miniussi, E., Jones, W. "Mechanochemical Synthesis of Multicomponent Crystals: One Liquid for One Polymorph? A Myth to Dispel", Crystal Growth and Design, 16(8), pp. 4582-4588, 2016. https://doi.org/10.1021/acs.cgd.6b00682

[50] Sharma, P., Zujovic, Z. D., Bowmaker, G. A., Denny, W. A., Garg, S. "Evaluation of a crystalline nanosuspension: Polymorphism, process induced transformation and in vivo studies", International Journal of Pharmaceutics, 408(1-2), pp. 138-151, 2011. https://doi.org/10.1016/j.ijpharm.2011.01.032

[51] Sawant, K. K., Patel, M. H., Patel, K. "Cefdinir nanosuspension for improved oral bioavailability by media milling technique: formulation, characterization and in vitro-in vivo evaluations", Drug Development and Industrial Pharmacy, 42(5), pp. 758-768, 2016. https://doi.org/10.3109/03639045.2015.1104344

[52] Malvern Panalytical "A basic guide to particle characterization", [online] Available at: https://www.malvernpanalytical.com/en/learn/knowledge-center/whitepapers/ WP120620BasicGuidePartChar [Accessed: 05 October 2019]

[53] Rawle, A. F. "The Basic Principles of Particle Size Analysis", Surface Coatings International Part A: Coatings Journal, 86, pp. 58-65, 2003.

[54] HORIBA Scientific "A Guidebook To Particle Size Analysis", HORIBA, Place of Publishing, Country, 2014. [online] Available at: https://www.horiba.com/fileadmin/uploads/Scientific/ Documents/PSA/PSA_Guidebook.pdf [Accessed: 10 April 2015]

[55] ASTM International "ASTM E799-03(2015): Standard Practice for Determining Data Criteria and Processing for Liquid Drop Size Analysis", ASTM International, West Conshohocken, PA, USA, 2015.

[56] Peltonen, L. "Design Space and QbD Approach for Production of Drug Nanocrystals by Wet Media Milling Techniques", Pharmaceutics, 10(3), Article Number: 104, 2018. https://doi.org/10.3390/pharmaceutics10030104

[57] Putri, D. C. A., Dwiastuti, R., Marchaban, M., Nugroho, A. K. "Optimization of Mixing Temperature and Sonication Duration", Jurnal Farmasi Sains Dan Komunitas: Journal of Pharmaceutical Sciences \& Community, 14(2), pp. 79-85, 2017. https://doi.org/10.24071/jpsc. 142728

[58] Jacobs, C., Müller, R. H. "Production and Characterization of a Budesonide Nanosuspension for Pulmonary Administration", Pharmaceutical Research, 19(2), pp. 189-194, 2002. https://doi.org/10.1023/A:1014276917363

[59] George, M., Ghosh, I. "Identifying the correlation between drug/ stabilizer properties and critical quality attributes (CQAs) of nanosuspension formulation prepared by wet media milling technology", European Journal of Pharmaceutical Sciences, 48(1-2), pp. 142-152, 2013.

https://doi.org/10.1016/j.ejps.2012.10.004 
[60] Zhao, Y. X., Hua, H. Y., Chang, M., Liu, W. J., Zhao, Y., Liu, H. M. "Preparation and cytotoxic activity of hydroxycamptothecin nanosuspensions", International Journal of Pharmaceutics, 392(1-2), pp. 64-71, 2010. https://doi.org/10.1016/j.ijpharm.2010.03.027

[61] Baka, E., Comer, J. E. A., Takács-Novák, K. "Study of equilibrium solubility measurement by saturation shake-flask method using hydrochlorothiazide as model compound", 46(2), pp. 335-341, 2008. https://doi.org/10.1016/j.jpba.2007.10.030

[62] Völgyi, G., Csicsák, D., Takács-Novák, K. "Right filter-selection for phase separation in equilibrium solubility measurement", European Journal of Pharmaceutical Sciences, 123, pp. 98-105, 2018. https://doi.org/10.1016/j.ejps.2018.06.031

[63] Rehbinder, P. A., Shchukin, E. D. "Surface phenomena in solids during deformation and fracture processs", Progress in Surface Science, 3(2), pp. 97-104, 1972.

https://doi.org/10.1016/0079-6816(72)90011-1
[64] Monteiro, A., Afolabi, A., Bilgili, E. "Continuous production of drug nanoparticle suspensions via wet stirred media milling: a fresh look at the Rehbinder effect", 39(2), pp. 266-283, 2013. https://doi.org/10.3109/03639045.2012.676048

[65] Eaqub Ali, M., Ullah, M., Bee Abd Hamid, S. "Surfactant-Assisted Ball Milling: a Novel Route To Novel Materials With Controlled Nanostructure -a Review", Reviews on Advanced Materials Science, 37, pp. 1-14, 2014.

[66] StatEase "Fit summary (RSM/MIX Model Selection)", [online] Available at: https://www.statease.com/docs/v11/contents/analysis/fit-summary/ [Accessed: 21 October 2019]

[67] Ding, Z., Wang, L., Xing, Y., Zhao, Y., Wang, Z., Han, J. "Enhanced Oral Bioavailability of Celecoxib Nanocrystalline Solid Dispersion based on Wet Media Milling Technique: Formulation, Optimization and In Vitro/In Vivo Evaluation", Pharmaceutics, 11(7), Article Number: 328, 2019. https://doi.org/10.3390/pharmaceutics11070328 